\title{
Astrocytes Are More Vulnerable than Neurons to Silicon Dioxide Nanoparticle Toxicity in Vitro
}

\author{
Jorge Humberto Limón-Pacheco ${ }^{1}$, Natalie Jiménez-Barrios ${ }^{2,3}$, Alejandro Déciga-Alcaraz ${ }^{3}{ }^{(0)}$, \\ Adriana Martínez-Cuazitl ${ }^{1}$ (D), Mónica Maribel Mata-Miranda ${ }^{1}$ (D), \\ Gustavo Jesús Vázquez-Zapién ${ }^{4}{ }^{D}$, Jose Pedraza-Chaverri ${ }^{5} \mathbb{D}$, Yolanda Irasema Chirino ${ }^{3}$ and $^{\circ}$ \\ Marisol Orozco-Ibarra $2, *$ (D) \\ 1 Laboratorio de Biología Celular y Tisular, Escuela Militar de Medicina, Centro Militar de Ciencias de la \\ Salud, Secretaría de la Defensa Nacional, Cerrada de Palomas S/N, Lomas de San Isidro, \\ Alcaldía Miguel Hidalgo, Ciudad de Mexico 11200, Mexico; akelason1977@gmail.com (J.H.L.-P.); \\ adyta0@hotmail.com (A.M.-C.); mmcmaribel@gmail.com (M.M.M.-M.) \\ 2 Laboratorio de Neurobiología Molecular y Celular, Instituto Nacional de Neurología y Neurocirugía, \\ Manuel Velasco Suárez, Av. Insurgentes Sur \# 3877, La Fama, Alcaldía Tlalpan, Ciudad de Mexico 14269, \\ Mexico; nataliej.k.barrios@gmail.com \\ 3 Laboratorio de Carcinogénesis y Toxicología, Unidad de Biomedicina, Facultad de Estudios Superiores \\ Iztacala, Universidad Nacional Autónoma de Mexico, Avenida de los Barrios \# 1, Los Reyes Iztacala, \\ Tlalnepantla, Estado de Mexico 54090, Mexico; alejandro.deciga01@gmail.com (A.D.-A.); \\ irasemachirino@gmail.com (Y.I.C.) \\ 4 Laboratorio de Embriología, Escuela Militar de Medicina, Centro Militar de Ciencias de la Salud, \\ Secretaría de la Defensa Nacional, Cerrada de Palomas S/N, Lomas de San Isidro, Alcaldía Miguel Hidalgo, \\ Ciudad de Mexico 11200, Mexico; gus1202@hotmail.com \\ 5 Departamento de Biología, Facultad de Química, Universidad Nacional Autónoma de Mexico, \\ Ciudad Universitaria, Alcaldía Coyoacán, Ciudad de Mexico 04510, Mexico; pedraza@unam.mx \\ * Correspondence: orozco_ibarra@ciencias.unam.mx; Tel.: +52-55-5606-3822 (ext. 2074)
}

Received: 30 June 2020; Accepted: 25 July 2020; Published: 29 July 2020

\begin{abstract}
Some studies have shown that silicon dioxide nanoparticles $\left(\mathrm{SiO}_{2}-\mathrm{NPs}\right)$ can reach different regions of the brain and cause toxicity; however, the consequences of $\mathrm{SiO}_{2}-\mathrm{NPs}$ exposure on the diverse brain cell lineages is limited. We aimed to investigate the neurotoxic effects of $\mathrm{SiO}_{2}-\mathrm{NP}(0-100 \mu \mathrm{g} / \mathrm{mL})$ on rat astrocyte-rich cultures or neuron-rich cultures using scanning electron microscopy, Attenuated Total Reflection-Fourier Transform Infrared spectroscopy (ATR-FTIR), FTIR microspectroscopy mapping (IQ mapping), and cell viability tests. $\mathrm{SiO}_{2}-\mathrm{NPs}$ were amorphous particles and aggregated in saline and culture media. Both astrocytes and neurons treated with $\mathrm{SiO}_{2}-\mathrm{NPs}$ showed alterations in cell morphology and changes in the IR spectral regions corresponding to nucleic acids, proteins, and lipids. The analysis by the second derivative revealed a significant decrease in the signal of the amide I ( $\alpha$-helix, parallel $\beta$-strand, and random coil) at the concentration of $10 \mu \mathrm{g} / \mathrm{mL}$ in astrocytes but not in neurons. IQ mapping confirmed changes in nucleic acids, proteins, and lipids in astrocytes; cell death was higher in astrocytes than in neurons $(10-100 \mu \mathrm{g} / \mathrm{mL})$. We conclude that astrocytes were more vulnerable than neurons to $\mathrm{SiO}_{2}-\mathrm{NPs}$ toxicity. Therefore, the evaluation of human exposure to $\mathrm{SiO}_{2}$-NPs and possible neurotoxic effects must be followed up.
\end{abstract}

Keywords: cerebellar granule neurons; nanoparticle exposure; neurotoxic effects; secondary astrocytes; silicon dioxide

\section{Introduction}

Silicon dioxide $\left(\mathrm{SiO}_{2}\right)$, labeled as E551 in Europe, has been authorized as a food additive for more than two decades. However, as nanotechnology develops, the use of $\mathrm{SiO}_{2}$ in nanometric size has 
increased [1] in the cosmetic and pharmaceutical industry due to its anti-caking properties. The growing potential exposure due to multiple sources in the environment has raised a global concern regarding the safety and possible adverse health effects of $\mathrm{SiO}_{2}$ nanoparticles $\left(\mathrm{SiO}_{2}-\mathrm{NPs}\right)$ by inhalation and oral exposure. Indeed, the European Food Safety Authority Panel on Food Additives and Nutrient Sources added to Food called to reassess the toxicity of $\mathrm{SiO}_{2}$ as a food additive in 2018 [2]. Mainly, crystalline $\mathrm{SiO}_{2}$ has been classified as a carcinogen to humans by the International Agency of Research in Cancer, and then, the possibility of adverse effects of amorphous $\mathrm{SiO}_{2}$ is under investigation. Some studies indicate that amorphous $\mathrm{SiO}_{2}$-NPs can be as reactive as crystalline particles, which may result in adverse health effects [3,4].

Additionally, $\mathrm{SiO}_{2}$-NPs are cytotoxic, genotoxic, immunotoxic, and induce cell death in several in vivo and in vitro experimental models [5]. $\mathrm{SiO}_{2}-\mathrm{NPs}$ can translocate to the bloodstream after inhalation [5,6]; even more, they can cross the placenta and reach the fetal brain and the liver as demonstrated in a mouse model [7]. Indeed, subchronic administration by nasal instillation of $\mathrm{SiO}_{2}-\mathrm{NPs}$ in adult rats resulted in NPs accumulation in the olfactory bulb, the striatum, the hippocampus, the brain stem, the cerebellum, and the frontal cortex [8], and some studies indicate an association to oxidative stress and inflammation $[9,10]$. Moreover, $\mathrm{SiO}_{2}-\mathrm{NPs}$ could disturb the structure and function of the blood-brain barrier by inducing inflammation through reactive oxygen species (ROS) generation and by activation of Rho-kinase/JNK signaling pathways [11]. Moreover, as NPs can reach the brain in different regions $[7,8]$ and based on the diversity of cell lineages, a differential vulnerability could be expected, for instance in neurons and astrocytes, two of the most relevant cell types for brain physiology. On the other hand, several techniques have been used to characterize the size, crystal structure, elemental composition, and other physical properties of NPs [12]. Fourier Transform Infrared spectroscopy (FTIR) is a technique based on the measurement of the absorption of electromagnetic radiation with wavelengths within the mid-infrared region (IR) $\left(4000-400 \mathrm{~cm}^{-1}\right)$ [12] that identifies variations in functional groups through the measure of the vibration and rotation of molecules influenced by IR [13]. The IR spectrum analysis has been used mainly to analyze pure samples, but biological interactions with $\mathrm{SiO}_{2}$-NPs can also be analyzed because molecular interactions produce a specific molecular fingerprint $[12,14]$. Thus, the present work aimed to study the neurotoxic effect of $\mathrm{SiO}_{2}-\mathrm{NPs}_{\mathrm{S}}$ on rat astrocyte-rich or rat neuron-rich cultures by Attenuated Total Reflection spectroscopy (ATR-FTIR) and FTIR microspectroscopy mapping (IQ mapping) to characterize biomolecular fingerprints and cellular susceptibility determining cell morphology and cell viability.

\section{Materials and Methods}

\subsection{Reagents}

We obtained $\mathrm{SiO}_{2}$-NPs catalog number 637,238 and most of the used reagents from Sigma-Aldrich (St. Louis, MO, USA). The $\mathrm{SiO}_{2}$-NPs used in this study were amorphous, non-crystalline, sized less than $100 \mathrm{~nm}$, and tend to agglomerate. All other reagents were of analytical grade and commercially available.

\subsection{Bioethics}

Rats used in this study were maintained and manipulated according the Norma Oficial Mexicana NOM-062-ZOO-1999, and a local Committee on Research Ethics approved the procedures to isolate astrocytes and neurons from neonatal rats (Approbation number at Instituto Nacional de Neurología y Neurocirugía: 19/17, date: 4 July 2017).

\subsection{Scanning Electron Microscopy (SEM) and Size Distribution}

The original size of $\mathrm{SiO}_{2}$-NPs was 10-20 nm, according to the Sigma-Aldrich data sheet (Cat. No.637238, St. Louis, MO, USA). Then, the shape was analyzed using a JSM-7800F Schottky Field Emission Scanning Electron Microscope (JEOL Ltd., Tokyo, Japan) with $3.0 \mathrm{kV}$ and 26 pixels/ $/ \mathrm{nm}^{2}$. The size distribution was measured using ImageJ software version 1.52a (1997-2018, National Institutes 
of Health, Bethesda, MD, USA). Briefly, the pixel size in each image was adjusted using the scale bar. The area of at least forty particles was registered. The area-equivalent average diameters of all the reported particles generated a number-based, cumulative particle size distribution.

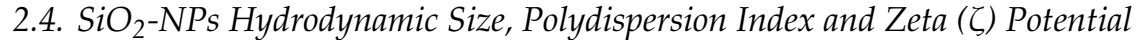

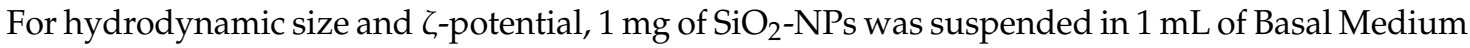
Eagle (BME) or Dulbecco's Modified Eagle Medium (DMEM) cell culture, and both were supplemented with $10 \%$ of fetal bovine serum (FBS) and $1 \%$ of antibiotic-antifungal GibcoTM, (Thermo Fisher Scientific, Waltham, MA, USA). Then, the suspension was sonicated at $60 \mathrm{~Hz}$ for $30 \mathrm{~min}$. Immediately, the stocks were diluted in a ratio of 1:100 in cell culture medium for hydrodynamic size measured by dynamic light scattering and for polydispersion index and $\zeta$-potential using a Zeta Plus Analyzer (Brookhaven Instruments, Holtsville, NY, USA).

\subsection{Secondary Culture of Rat Cerebellar Astrocytes}

We isolated rat astrocyte-rich secondary cultures following a previously reported protocol with minor modifications [15]. In brief, astrocytes were isolated from the cerebellum of 7-9-days-old male/female Wistar rats. Cerebellum was suspended in Tyrode solution and disintegrated by passing through a $21 \mathrm{G} \times 32 \mathrm{~mm}$ needle three times and then through a $27 \mathrm{G} \times 13 \mathrm{~mm}$ needle three more times. Then, it was incubated $15 \mathrm{~min}$ at $37{ }^{\circ} \mathrm{C}$ and centrifuged at $500 \times g$ to pellet the resulting cerebellar dissociated cells, which were suspended in DMEM medium supplemented with 10\% FBS and antibiotic-antimycotic GibcoTM (Thermo Fisher Scientific, Waltham, MA, USA). Then, the mixed cerebellar cells were plated in T75 flasks previously treated with $10 \mu \mathrm{g} / \mathrm{mL}$ poly-D-lysine, and the cell culture medium was changed every four days. After 28 days, when astrocytes were confluent, the T75 flasks were placed on an orbital shaker incubator at $180 \mathrm{rpm}$ for $24 \mathrm{~h}$ to remove microglia and other glial cells. Then, DMEM was discarded, and astrocytes were washed and incubated with $0.5 \%$ Trypsin-EDTA for $5 \mathrm{~min}$ at $37^{\circ} \mathrm{C}$. After astrocytes were detached from the culture flask, they were suspended in fresh supplemented DMEM and reseeded at $16 \times 10^{3} \mathrm{cells} / \mathrm{cm}^{2}$ in 24-well plates to obtain astrocyte-rich cultures. The identity of these cultures was confirmed through a GFAP immunodetection (Figure S1A).

\subsection{Primary Culture of Rat Cerebellar Granule Neurons}

We isolated rat cerebellar granule neuron-rich cultures from the cerebellum of 7-9-days-old male/female Wistar rats following standardized protocols [16]. Briefly, the cerebellum was removed, cut within small pieces, and incubated with $0.25 \%$ trypsin solution by $10 \mathrm{~min}$ at $37{ }^{\circ} \mathrm{C}$. Then, $0.08 \%$ DNase I was added to degrade the free DNA, and tissue was dissociated by filtration through a sterile polyester mesh of $50 \mu \mathrm{m}$ pore size. Cells were suspended in BME supplemented with 10\% BSA, 2 mM L-glutamine, and antibiotic-antifungal GibcoTM (Thermo Fisher Scientific, Waltham, MA, USA). A total of $300 \times 10^{3} \mathrm{cells} / \mathrm{cm}^{2}$ were seeded in 24 -well plates previously coated with $5 \mu \mathrm{g} / \mathrm{mL}$ poly-L-lysine. Cytosine arabinose $(10 \mu \mathrm{M})$ was added after $24 \mathrm{~h}$, and glucose $(5 \mathrm{mM})$ after four days from seeding. According to a morphological examination followed by immunodetection studies using antibodies against the glial fibrillary acidic protein (GFAP, Millipore Co, Burlington, MA, USA), microtubule-associated protein 2 (MAP-2, Millipore Co, Burlington, MA, USA), and 4',6-diamidino-2-phenylindole (DAPI, Thermo Fisher Scientific, Waltham, MA, USA), glial, neuronal, and nuclear markers, respectively, about $2 \%$ of glial cells are present in our culture conditions (Figure S1B).

\subsection{Concentration-Response Analysis to $\mathrm{SiO}_{2}-\mathrm{NPS}$}

Astrocyte-rich cultures were exposed to $\mathrm{SiO}_{2}-\mathrm{NPs}$ at day two after reseeding, when reached at least $80 \%$ of confluence, whereas neurons were exposed to $\mathrm{SiO}_{2}-\mathrm{NPs}$ after 9 days of culture. A stock solution of $1 \mathrm{mg} / \mathrm{mL} \mathrm{SiO}_{2}$-NPs was done in DMEM medium or BME (for astrocytes or neurons, 
respectively) and then was sonicated at $37^{\circ} \mathrm{C}$ for $30 \mathrm{~min}$ at $50 / 60 \mathrm{~Hz}$ in a 2200 ultrasonic Cleaner, (Branson Ultrasonics, Danbury, CT, USA). Cell cultures were exposed to 0, 1, 10, 25, 50, and $100 \mu \mathrm{g} / \mathrm{mL}$ of $\mathrm{SiO}_{2}-\mathrm{NPs}$ by $24 \mathrm{~h}$ in fresh DMEM for astrocytes and conditioned medium for neurons. Bright-field images were obtained for each condition through a Nikon microscope with NIS-Elements software (Nikon Instruments Inc., Melville, NY, USA).

\subsection{ATR-FTIR Spectroscopy}

FTIR spectral analysis was conducted in the spectral range between $4000-400 \mathrm{~cm}^{-1}$ using a Jasco FT/IR-6600 spectrometer (Jasco Corporation, Tokyo, Japan) in the ATR-FTIR sampling mode. For $\mathrm{SiO}_{2}$-NPs FTIR analysis, a small amount of dry or saline-suspended $\mathrm{SiO}_{2}-\mathrm{NPs}_{\text {s }}$ was deposited onto the surface of the ATR crystal and dried at room temperature for 12 min to eliminate water excess. Control or treated cells were washed twice with saline $(0.9 \% \mathrm{NaCl})$ and suspended in $50 \mu \mathrm{L}$ of fresh saline solution. A sample of $4 \mu \mathrm{L}$ of cell suspension was deposited onto the surface of the ATR-FTIR crystal and air-dried, as mentioned before. The spectrum for each sample was the average of 240 data acquisitions. Once all FTIR spectra were acquired (raw spectra), a standard normal variate normalization process was applied by using UNSCRAMBLER X, Version 10.3 (CAMO Analytics, Montclair, NJ, USA, 2011). After, the calculation of the second derivative of each spectrum was performed through the Savitzky-Golay algorithm, which uses a fitting successive subset of adjacent data points with a small degree polynomial by linear least squares as has been reported [17]. The spectral data were plotted using Origin (Pro), Version 6.0 (OriginLab Corporation, Northampton, MA, USA, 1999).

\subsection{FTIR Microspectroscopy Mapping (IQ Mapping)}

Biochemical changes in lipids, proteins, and nucleic acids in astrocyte-rich cultures and neuron-rich cultures exposed to $\mathrm{SiO}_{2}$-NPs were studied by FTIR microspectroscopy mapping, as previously reported with minor modifications [18]. FTIR microspectroscopy produces maps of color derived either directly from distinct spectral parameters in the sample, such as the functional groups of biomolecules, from multiple points in a specified area in a biological specimen. Biochemical images were obtained using the automated mapping of multiple points (IQ mapping) function of the FTIR microscope Jasco IRT-5200 coupled to a Jasco FT/IR-6600 spectrometer (Jasco Corporation, Tokyo, Japan) and a liquid nitrogen-cooled Mercury, Cadmium, Tellurium detector. In this function, the complete system automatically scans a specified area of a cell sample, collecting a full spectrum of each point without moving the sample with a $32 \times$ Cassegrain objective. Briefly, a sample of $4 \mu \mathrm{L}$ of the suspended cells control or treated was deposited on a low reflective glass slide and dispersed to form a monolayer of cells and air-dried at room temperature for $12 \mathrm{~min}$ to remove water excess. The acquisition of images was performed in the reflectance mode with a spectral resolution of $4 \mathrm{~cm}^{-1} 60$ scans and the spectral range of $400-4000 \mathrm{~cm}^{-1}$. The spectra were baseline corrected to compensate for atmospheric changes and ensure that the probe was free of cellular material using a free cells field in the low reflective glass slide as a background. The analyzed regions of the spectra were $989-1185 \mathrm{~cm}^{-1}$ for nucleic acids, $1593-1712 \mathrm{~cm}^{-1}$ for secondary structure of proteins, and $2830-2945 \mathrm{~cm}^{-1}$ for lipids. The analysis of each spectral region was represented as a tridimensional area, corresponding to the density distribution of the specimen's biochemical components. The color scales for the maps were adjusted employing the same color for each biochemical component represented and taking care that scales were comparable between the experimental groups.

\subsection{Cell Viability Tests}

The calcein-AM uptake (Thermo Fisher Scientific, Waltham, MA, USA) and the 3-(4,5-dimethylthiazol -2-yl)-2,5-diphenyltetrazolium bromide (MTT) reduction assays were used to evaluate the astrocytes and neurons viability. Living neurons uptake the cell-permeant dye calcein-AM and emit green fluorescence after its hydrolysis by the activity of cytoplasmic esterases. MTT is transformed into 
formazan blue by the activity of mitochondrial dehydrogenases, and absorbance has been reported directly proportional to the number of viable cells [19]. For calcein-AM uptake, cells were washed three times with a Tyrode solution $\mathrm{pH}=7.4$. Calcein- $\mathrm{AM}(2.5 \mu \mathrm{g} / \mathrm{mL})$ solution was immediately added, and cells were incubated for $30 \mathrm{~min}$ at $37^{\circ} \mathrm{C}$ and $5 \% \mathrm{CO}_{2}$ in darkness. The cells were washed three more times with Tyrode solution, and fluorescence was measured at $485 \mathrm{~nm}$ excitation and $585 \mathrm{~nm}$ emission in a multimodal microplate reader (BioTek Instruments, Winooski, VT, USA). The increase in fluorescence indicates the calcein-AM uptake by the cells. For MTT reduction assay, a solution of $1 \mathrm{mg} / \mathrm{mL}$ MTT in phosphate buffer was prepared. This solution was diluted with either BME or DMEM medium in a proportion of $500 \mu \mathrm{L}$ of medium per $250 \mu \mathrm{L}(2: 1)$ of MTT per well. After the MTT addition, the culture plate was incubated for one hour at $37^{\circ} \mathrm{C}$, and then the remaining MTT was removed. The formazan crystals precipitated in the wells were dissolved with $500 \mu \mathrm{L}$ of isopropanol. The formazan absorbance was quantified at $570 \mathrm{~nm}$ in a multimodal microplate reader (BioTek Instruments, Winooski, VT, USA). Data were expressed as the percentage of calcein-AM uptake or MTT reduction in control wells.

\subsection{Statistical Analysis}

All the experiments were independently performed at least three times with three technical replicates. The results were expressed as mean \pm SEM. Statistical significance was determined by one-way ANOVA followed by Tukey's post hoc test or by two-way ANOVA followed by Bonferroni's post hoc test, as appropriate, using the GraphPad Prism 6.0 software (San Diego CA, USA, 2012). Statistical difference was considered when the value of $p<0.05$.

\section{Results}

\subsection{FTIR and SEM Characterization of $\mathrm{SiO}_{2}-\mathrm{NPS}$}

When nanoparticles are suspended in any medium, the properties of the material get modified to a great extent [20]. Due to this nanoparticles' property, we analyzed by ATR-FTIR the spectral properties of the pure powder and the one suspended in $0.9 \% \mathrm{NaCl} \mathrm{SiO}_{2}-\mathrm{NPs}$. Selection of $\mathrm{NaCl} 0.9 \%$ as a resuspension media obey the priority of avoiding interference or noisy signal in spectral regions evaluated, and because after exposure to concentrations of $\mathrm{SiO}_{2}-\mathrm{NPs}$, we washed, collected, and stored cells in $\mathrm{NaCl} 0.9 \%$. The analysis by FTIR of $\mathrm{SiO}_{2}-\mathrm{NPs}$ dry powder showed a spectral band region of $400-1700 \mathrm{~cm}^{-1}$ (Figure 1a). The absorption bands observed correspond to $458 \mathrm{~cm}^{-1}$ to Si-O out of plane deformation, $800 \mathrm{~cm}^{-1}$ to Si-O bending, $961 \mathrm{~cm}^{-1}$ to Si-OH stretching, $1083 \mathrm{~cm}^{-1}$ to Si-O-Si asymmetric stretching (Figure 1a,c). This set of spectral bands is characteristic of $\mathrm{SiO}_{2}$ and is similar to the spectral bands available in the PubChem Database and SpectraBase for the pure compound. Bands of $1638 \mathrm{~cm}^{-1}$ for $\mathrm{C}-\mathrm{O}$ bending and $3361 \mathrm{~cm}^{-1}$ for $-\mathrm{OH}$ stretching was also detected (Figure $1 \mathrm{a}, \mathrm{c}$ ). When $\mathrm{SiO}_{2}-\mathrm{NPs}$ were suspended in saline solution, spectral bands detected were $477 \mathrm{~cm}^{-1}$ for Si-O out of plane deformation, $801 \mathrm{~cm}^{-1}$ for Si-O bending, $970 \mathrm{~cm}^{-1}$ for Si-OH stretching, $1097 \mathrm{~cm}^{-1}$ for Si-O-Si asymmetric stretching (Figure $1 \mathrm{~b}$ ). For the $-\mathrm{OH}$ stretching band, the spectral band corresponded to $3359 \mathrm{~cm}^{-1}$. Under this condition, no absorption band for $\mathrm{C}-\mathrm{O}$ bending was detected (Figure 1c). Moreover, as in the case of the pure powder of $\mathrm{SiO}_{2}-\mathrm{NPs}$ suspended in saline solution, the band corresponding to Si-C stretching was not detected (Figure $1 \mathrm{~b}, \mathrm{c}$ ). The spectral band of $1083 \mathrm{~cm}^{-1}$ for $\mathrm{Si}-\mathrm{O}-\mathrm{Si}$ asymmetric stretching is the most characteristic band for $\mathrm{SiO}_{2}-\mathrm{NPs}$.

On the other hand, according to the manufacturer, the $\mathrm{SiO}_{2}-\mathrm{NPs}$ used in the present study have an original size of 10-20 nm determined by Brunauer-Emmett-Teller (BET) surface area analysis. In this study, the analysis of $\mathrm{SiO}_{2}$-NPs by SEM displayed an amorphous shape and sized below $100 \mathrm{~nm}$ (Figure 1d). When the $\mathrm{SiO}_{2}-\mathrm{NPs}$ were suspended in culture media, the hydrodynamic size of $\mathrm{SiO}_{2}-\mathrm{NPs}$ dispersed in BME and DMEM were of $251.3 \pm 78.75 \mathrm{~nm}$ and $416 \pm 152 \mathrm{~nm}$, respectively. The $\zeta$-potential of $\mathrm{SiO}_{2}$-NPs in BME was $7.48 \mathrm{mV}$ and in DMEM was $7.21 \mathrm{mV}$ (Figure 1d). Finally, the polydispersion index was $0.84 \pm 0.14$ for $\mathrm{SiO}_{2}$-NPs in $\mathrm{BME}$ and $0.69 \pm 0.11$ for $\mathrm{SiO}_{2}-\mathrm{NPs}$ dispersed in DMEM. 
a
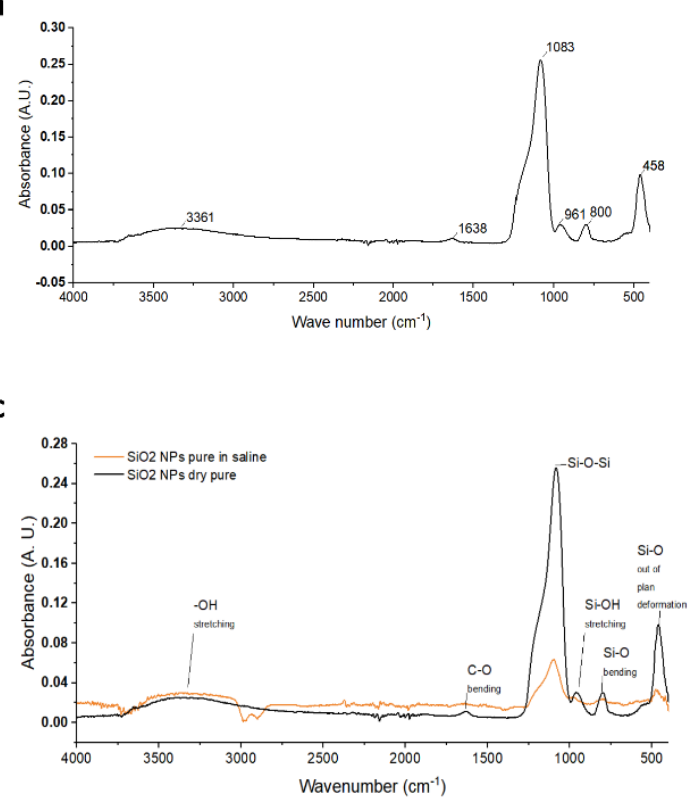

b

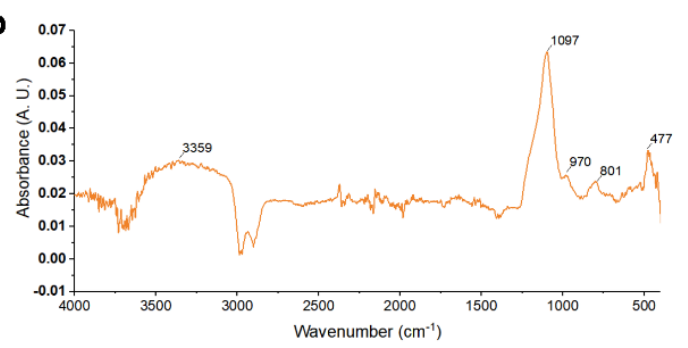

d

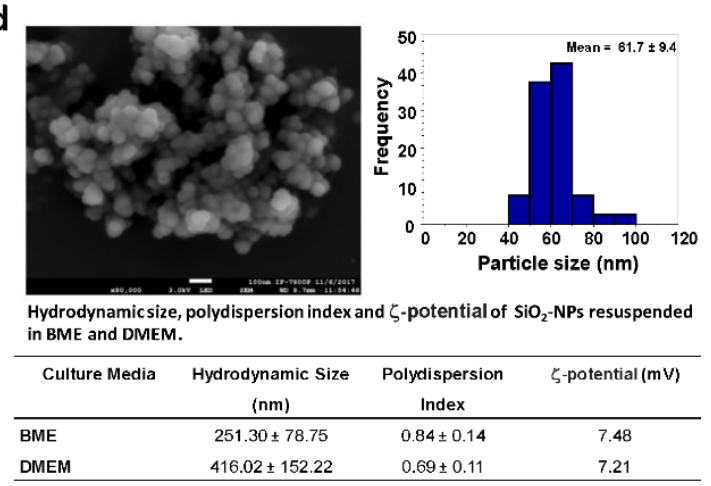

Figure 1. Characterization of $\mathrm{SiO}_{2}-\mathrm{NPs}$ by ATR-FTIR spectroscopy, scanning electron microscopy, and $\zeta$-potential. (a) An infrared spectrum of $\mathrm{SiO}_{2}-\mathrm{NPs}$ as pure powder. IR spectral bands correspond to $458 \mathrm{~cm}^{-1}$ for Si-O out of plane deformation; $800 \mathrm{~cm}^{-1}$ for Si-O bending, $961 \mathrm{~cm}^{-1}$ for Si-OH stretching, $1083 \mathrm{~cm}^{-1}$ for Si-O-Si asymmetric stretching, $1638 \mathrm{~cm}^{-1}$ for C-O bending, $3361 \mathrm{~cm}^{-1}$ of $-\mathrm{OH}$. (b) An infrared spectrum of $\mathrm{SiO}_{2}$-NPs suspended in saline solution. (c) Comparison of spectral bands of pure powder $\mathrm{SiO}_{2}-\mathrm{NPs}$ vs. suspended in saline. (d) Representative image of the scanning electron microscopy and $\zeta$-potential values of $\mathrm{SiO}_{2}$-NPs suspended in BME and DMEM. The SEM image shown corresponds to $80,000 \times$, scale bar $100 \mathrm{~nm}$.

\subsection{Morphological Changes of Rat Cerebellar Astrocytes and Neurons Exposed to $\mathrm{SiO}_{2}-\mathrm{NPS}$}

Control astrocytes possessed branching processes or long and thin unbranched processes, also showed flat and epithelioid morphology, arranged in monoculture, with scarce or null syncytium formed with other astrocytes (Figure 2a). After exposure to concentrations of 1, 10, and $25 \mu \mathrm{g} / \mathrm{mL} \mathrm{SiO}_{2}-\mathrm{NPs}_{\text {, }}$ astrocytes showed subtle morphological differences compared to control. However, astrocytes treated with $50 \mu \mathrm{g} / \mathrm{mL} \mathrm{SiO}_{2}$-NPs showed marked changes in morphology, such as very thin, long, and scarce developed ramifications and small soma. Exposure to $100 \mu \mathrm{g} / \mathrm{mL} \mathrm{SiO}_{2}-\mathrm{NPs}$ resulted in a markedly decreased size number of astrocytes compared with the control (Figure 2a). Meanwhile, control neurons showed long and abundant neurites, ramified and extensive (Figure 3a). In the neurons exposed to $10 \mu \mathrm{g} / \mathrm{mL} \mathrm{SiO}_{2}$-NPs, small soma size and poor development of neurites were observed. From this concentration, loss of network conformation formed by the ramifications and thin and shortened cellular extensions were observed (Figure 3a).

\subsection{ATR-FTIR Spectra of Rat Cerebellar Astrocytes and Neurons Exposed to $\mathrm{SiO}_{2}-\mathrm{NPS}$}

Analysis of biological samples through FTIR is possible thanks to specific regions of the IR spectrum that represent a biochemical fingerprint of the structure and function of specific biomolecules of interest in cellular specimens. In our study, we considered the fingerprint region of $\mathrm{SiO}_{2}-\mathrm{NPs}$ $600-1450 \mathrm{~cm}^{-1}$ observed previously (Figure 1a-c), which also includes nucleic acids and carbohydrates. Proteins are represented by the amide I and amide II region of $1500-1700 \mathrm{~cm}^{-1}$ and lipids by the higher region of $2550-3500 \mathrm{~cm}^{-1}$ associated with stretching vibrations of $-\mathrm{CH}_{2}$ [14]. A representative normalized IR spectrum for each experimental condition is shown in Figure S2, where we observed slight differences in the value of the normalized IR spectral band corresponding to $-\mathrm{CH}_{2}$ region of 
lipids, amide I region of proteins, and the $\mathrm{PO}_{2}{ }^{-}$region of nucleic acids and carbohydrates between $\mathrm{SiO}_{2}-\mathrm{NPs}$ concentrations. A summary of the main IR spectral bands detected for astrocytes and neurons is presented in Supplementary Table S1.

a

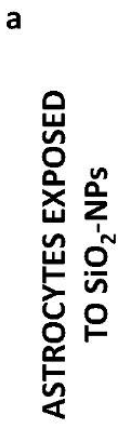

b

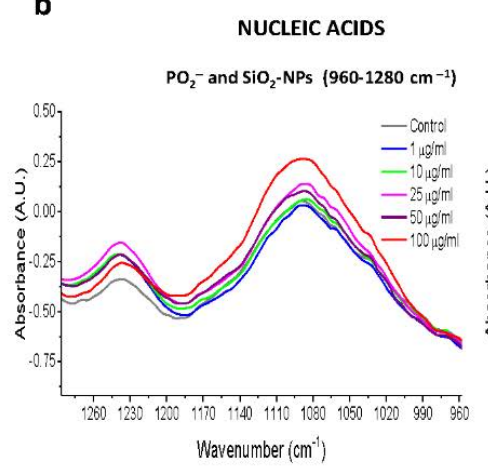

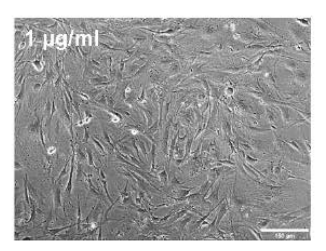

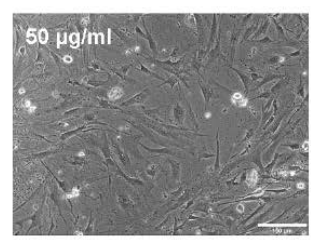

PROTEINS

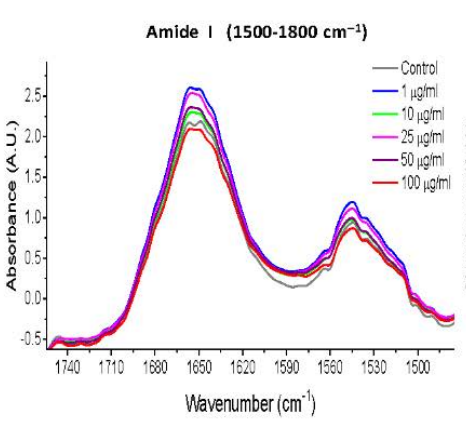

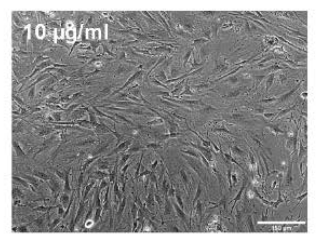

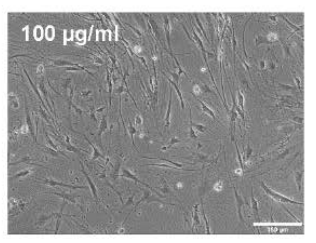

LIPIDS

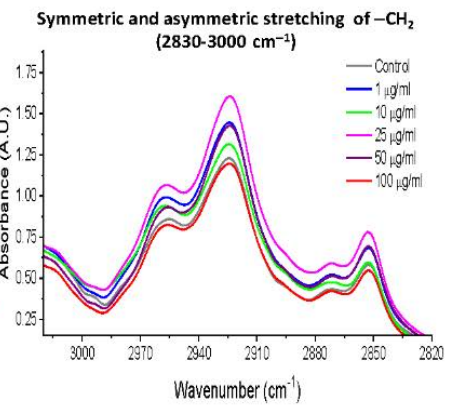

Figure 2. Morphological changes and normalized IR spectra of primary cultures of astrocytes exposed to $\mathrm{SiO}_{2}$-NPs. (a) Astrocyte morphology after $24 \mathrm{~h}$ of $\mathrm{SiO}_{2}-\mathrm{NPs}$ exposure. Images were obtained by light microscopy. Each treatment was performed at least in triplicate $(n=3)$ with three technical replicates. Subtle morphological changes compared to control culture are appreciated at 1,10 , and $25 \mu \mathrm{g} / \mathrm{mL}$ $\mathrm{SiO}_{2}$-NPs. At $50 \mu \mathrm{g} / \mathrm{mL}$ and $100 \mu \mathrm{g} / \mathrm{mL} \mathrm{SiO}_{2}$-NPs, the size and amount of the astrocytes decreased markedly in comparison with the control. Scale bar: $150 \mu \mathrm{m}$. (b) Normalized IR spectra of astrocytes exposed to $\mathrm{SiO}_{2}-\mathrm{NPs}$. The spectral region of $960-1280 \mathrm{~cm}^{-1}$ corresponds to $\mathrm{PO}_{2}$ - (nucleic acids) and $\mathrm{SiO}_{2}-\mathrm{NPs} ; 1500-1800 \mathrm{~cm}^{-1}$ is the spectral region that contains the amide I spectral bands and representative bands of the secondary protein structure; $2830-3000 \mathrm{~cm}^{-1}$ includes the spectral bands of symmetric lipid $\mathrm{CH}_{2}$ and asymmetric $\mathrm{CH}_{2}$. The spectral images are representative of four independent experiments performed with each treatment, with three technical replicates.

Next, we analyzed the normalized IR spectrum and its absorbance in spectral bands of the nucleic acids, protein, and lipid regions (Figures $2 \mathrm{~b}$ and $3 \mathrm{~b}$ ). In astrocytes, the changes in the IR spectral bands and the absorbance were independent of the increase in the concentration of $\mathrm{SiO}_{2}-\mathrm{NPs}$ for the three spectral regions analyzed (Figure 2b). We found a significant difference in the absorbance in the $\mathrm{PO}_{2}{ }^{-}$ symmetric region at $1090 \mathrm{~cm}^{-1}\left(p=0.025, F_{(5,42)}=2.888\right.$, Figure $\left.2 \mathrm{~b}\right)$; and the amide I at $1650 \mathrm{~cm}^{-1}$ of protein region $\left(p=0.0409, F_{(5,42)}=2.567\right)$. In the amide II region, no differences were detected (Figure $2 \mathrm{~b})$. No differences were observed in the lipid region $\left(\mathrm{C}=\mathrm{O}, 1744 \mathrm{~cm}^{-1} ;-\mathrm{CH}_{2}\right.$ symmetric $2852 \mathrm{~cm}^{-1}$ and asymmetric $2923 \mathrm{~cm}^{-1}$ ). In the case of neurons, there were changes in the IR spectral band and absorbance in the nucleic acids, protein, and lipid regions (Figure $3 b$ ). The difference in the spectral band corresponding to the nucleic acids asymmetric $\mathrm{PO}_{2}-$ at $1237 \mathrm{~cm}^{-1}$ was detected $\left(p=0.0015, F_{(5,60)}=4.510\right)$ without significant changes in the absorbance (Figure $\left.3 \mathrm{~b}\right)$. No changes were observed in the spectral region of amide I at $1652 \mathrm{~cm}^{-1}$, amide II at $1545 \mathrm{~cm}^{-1}$ (Figure $3 b$ ), or C=O at $1740 \mathrm{~cm}^{-1}$ to lipids. The absorbance in the asymmetric $-\mathrm{CH}_{2}$ lipid region at $2923 \mathrm{~cm}^{-1}$ was different among concentrations $\left(p=0.010, F_{(5,60)}=3.318\right)$, but no changes in the IR spectral band were observed. 
Taken together, all changes described in these spectral bands' positions and absorbances indicated the biological interaction between $\mathrm{SiO}_{2}-\mathrm{NPs}$ and biochemical components of astrocytes and neurons.

a

b

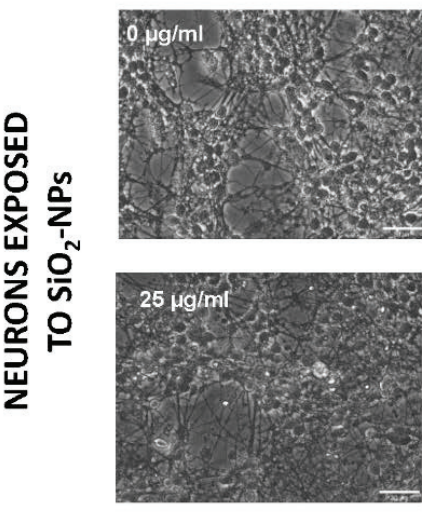

NUCLEIC ACIDS

$\mathrm{PO}_{2}^{-}$and $\mathrm{SiO}_{2}-\mathrm{NPS}\left(960-1280 \mathrm{~cm}^{-1}\right)$
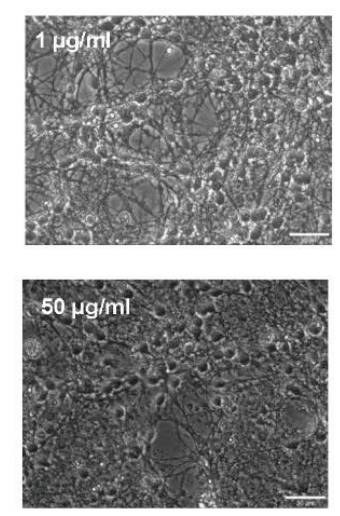

PROTEINS

Amide I $\left(1500-1800 \mathrm{~cm}^{-1}\right)$

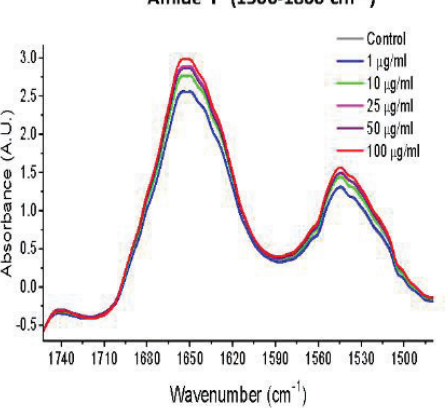

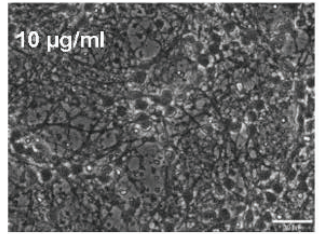

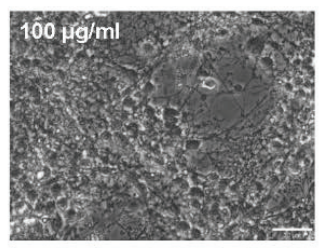

LIPIDS

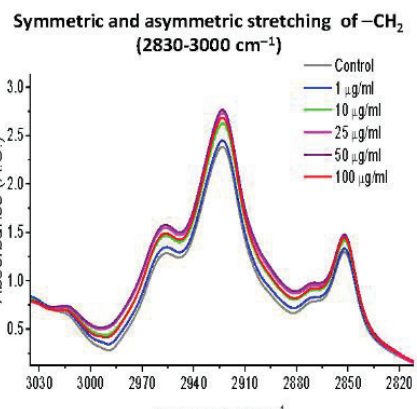

Figure 3. Morphological changes and normalized IR spectra of the primary cultures of neurons exposed to $\mathrm{SiO}_{2}$-NPs. (a) Neuron morphology after $24 \mathrm{~h}$ of $\mathrm{SiO}_{2}-\mathrm{NPs}$ exposure. Images were obtained by light microscopy. Each treatment was performed at least in triplicate $(n=3)$ with three technical replicates. There are no morphological changes in the concentrations of $0-25 \mu \mathrm{g} / \mathrm{mL}$, but at 50 and $100 \mu \mathrm{g} / \mathrm{mL}$, there are clear morphological changes such as a reduced cell volume and a decrease in the amount of cells. Scale bar: $150 \mu \mathrm{m}$. (b) Normalized IR spectra of neurons exposed to $\mathrm{SiO}_{2}-\mathrm{NPs}_{\text {. The spectral }}$ region of $960-1280 \mathrm{~cm}^{-1}$ corresponds to $\mathrm{PO}_{2^{-}}$(nucleic acids) and $\mathrm{SiO}_{2}-\mathrm{NPs}, 1500-1800 \mathrm{~cm}^{-1}$ to spectral region that contains the amide I spectral bands and representative bands of the secondary protein structure, and $2830-3000 \mathrm{~cm}^{-1}$ includes the spectral bands of symmetric lipid $\mathrm{CH}_{2}$ and asymmetric $\mathrm{CH}_{2}$. The spectral images are representative of four independent experiments performed with each treatment, with three technical replicates.

\subsection{Second Derivative Analyses of Spectral Bands}

FTIR spectra of biological samples require a more in-depth examination because of their biochemical and molecular complexity, and changes in the absorbance of spectral bands of interest could be underestimated [21]. For that reason, the second derivative was used to analyze spectral bands that potentially overlapped in the IR spectrum of each $\mathrm{SiO}_{2}-\mathrm{NPs}$ concentration. Bands of particular interest due to their biological importance considered in this study were $1083 \mathrm{~cm}^{-1}$ to examine the incorporation of $\mathrm{SiO}_{2}-\mathrm{NPs}$ in rat astrocytes and neurons in agreement with the spectral fingerprint of the $\mathrm{SiO}_{2}-\mathrm{NPs}$ previously presented; $1090 \mathrm{~cm}^{-1}$ to evaluate changes in symmetric stretching $\mathrm{PO}_{2}{ }^{-}$ of sugar rings of nucleic acids, mainly DNA, and as an indicator of cell death [22]; and $1654 \mathrm{~cm}^{-1}$, $1639 \mathrm{~cm}^{-1}$, and $1627 \mathrm{~cm}^{-1}$ as indicators of changes in the proteins secondary structure corresponding to alpha-helix, random coil, and parallel beta-strand, respectively [23]. Spectral bands of $2852 \mathrm{~cm}^{-1}$ and $2923 \mathrm{~cm}^{-1}$ are representative of symmetric and asymmetric stretching of $-\mathrm{CH}_{2}$ of lipids, respectively, and have been previously considered as biomarkers of cell death [22]. A summary of the values obtained through the second derivative analysis is shown in Table 1. 
Table 1. Second derivative analysis of spectral bands $\left(\mathrm{cm}^{-1}\right)$ of chemical bond for nucleic acids, protein and lipid regions of rat astrocytes and neurons exposed to $\mathrm{SiO} 2-\mathrm{NPs}$.

\begin{tabular}{|c|c|c|c|c|c|c|c|c|}
\hline \multirow{2}{*}{$\begin{array}{c}\text { Cell Type/Chemical } \\
\text { Bond }\end{array}$} & \multicolumn{8}{|c|}{ Concentration of $\mathrm{SiO}_{2}-\mathrm{NPs}(\mu \mathrm{g} / \mathrm{mL})$} \\
\hline & & 0 & 1 & 10 & 25 & 50 & 100 & \\
\hline \multicolumn{9}{|l|}{ Astrocytes } \\
\hline Vibration & Spectral Band & $n=8$ & $n=8$ & $n=8$ & $n=8$ & $n=8$ & $n=8$ & ANOVA \\
\hline $\mathrm{SiO}_{2}-\mathrm{NPs}$ & $1083 \mathrm{~cm}^{-1}$ & $0.023 \pm 0.010$ & $0.019 \pm 0.008$ & $0.014 \pm 0.003 \S$ & $0.017 \pm 0.006$ & $0.020 \pm 0.006$ & $0.028 \pm 0.011$ & 0.0177 * \\
\hline Symmetric $\mathrm{PO}_{2}^{-}$ & $1090 \mathrm{~cm}^{-1}$ & $0.024 \pm 0.011$ & $0.019 \pm 0.008$ & $0.013 \pm 0.003 \S$ & $0.017 \pm 0.006$ & $0.020 \pm 0.007$ & $0.027 \pm 0.012$ & 0.0211 * \\
\hline Parallel beta strand & $1627 \mathrm{~cm}^{-1}$ & $0.026 \pm 0.010$ & $0.021 \pm 0.008$ & $0.015 \pm 0.003 \S$ & $0.019 \pm 0.005$ & $0.022 \pm 0.006$ & $0.029 \pm 0.011$ & 0.0167 * \\
\hline Random coil & $1639 \mathrm{~cm}^{-1}$ & $0.031 \pm 0.012$ & $0.026 \pm 0.008$ & $0.019 \pm 0.003 \S$ & $0.023 \pm 0.005$ & $0.025 \pm 0.007$ & $0.033 \pm 0.011$ & 0.0241 * \\
\hline Alpha Helix & $1654 \mathrm{~cm}^{-1}$ & $0.034 \pm 0.012$ & $0.030 \pm 0.009$ & $0.022 \pm 0.003 \S$ & $0.026 \pm 0.005$ & $0.029 \pm 0.008$ & $0.036 \pm 0.010$ & $0.0246^{*}$ \\
\hline Symmetric $-\mathrm{CH}_{2}$ & $2852 \mathrm{~cm}^{-1}$ & $0.029 \pm 0.010$ & $0.026 \pm 0.009$ & $0.019 \pm 0.003 \S$ & $0.025 \pm 0.004$ & $0.026 \pm 0.008$ & $0.033 \pm 0.011$ & 0.0452 * \\
\hline $\begin{array}{l}\text { Asymmetric }-\mathrm{CH}_{2} \\
\text { Neurons }\end{array}$ & $2923 \mathrm{~cm}^{-1}$ & $0.029 \pm 0.010$ & $0.025 \pm 0.008$ & $0.019 \pm 0.003 \S$ & $0.024 \pm 0.004$ & $0.026 \pm 0.008$ & $0.032 \pm 0.011$ & 0.0292 * \\
\hline Vibration & Spectral Band & $n=11$ & $n=11$ & $n=11$ & $n=11$ & $n=11$ & $n=11$ & ANOVA \\
\hline $\mathrm{SiO}_{2}-\mathrm{NPs}$ & $1083 \mathrm{~cm}^{-1}$ & $0.012 \pm 0.003$ & $0.014 \pm 0.006$ & $0.014 \pm 0.004$ & $0.012 \pm 0.003$ & $0.013 \pm 0.004$ & $0.015 \pm 0.007$ & 0.5955 \\
\hline Symmetric $\mathrm{PO}_{2}^{-}$ & $1090 \mathrm{~cm}^{-1}$ & $0.012 \pm 0.003$ & $0.014 \pm 0.007$ & $0.014 \pm 0.004$ & $0.013 \pm 0.003$ & $0.014 \pm 0.004$ & $0.016 \pm 0.007$ & 0.5404 \\
\hline Parallel beta strand & $1627 \mathrm{~cm}^{-1}$ & $0.015 \pm 0.003$ & $0.018 \pm 0.006$ & $0.018 \pm 0.004$ & $0.016 \pm 0.003$ & $0.017 \pm 0.003$ & $0.019 \pm 0.007$ & 0.4314 \\
\hline Random coil & $1639 \mathrm{~cm}^{-1}$ & $0.016 \pm 0.003$ & $0.019 \pm 0.008$ & $0.019 \pm 0.005$ & $0.017 \pm 0.003$ & $0.018 \pm 0.00$ & $0.020 \pm 0.007$ & 0.5086 \\
\hline Alpha Helix & $1654 \mathrm{~cm}^{-1}$ & $0.021 \pm 0.004$ & $0.024 \pm 0.008$ & $0.024 \pm 0.005$ & $0.028 \pm 0.003$ & $0.024 \pm 0.004$ & $0.027 \pm 0.008$ & 0.3475 \\
\hline Symmetric $-\mathrm{CH}_{2}$ & $2852 \mathrm{~cm}^{-1}$ & $0.028 \pm 0.003$ & $0.030 \pm 0.007$ & $0.031 \pm 0.004$ & $0.030 \pm 0.003$ & $0.031 \pm 0.004$ & $0.033 \pm 0.008$ & 0.4128 \\
\hline Asymmetric $-\mathrm{CH}_{2}$ & $2923 \mathrm{~cm}^{-1}$ & $0.026 \pm 0.003$ & $0.028 \pm 0.007$ & $0.029 \pm 0.004$ & $0.028 \pm 0.003$ & $0.029 \pm 0.004$ & $0.030 \pm 0.008$ & 0.4027 \\
\hline
\end{tabular}

* One-way ANOVA indicates difference among groups, $p<0.05$; § Difference between $\mathrm{SiO}_{2}$-NPs concentration $10 \mathrm{vs.} 100 \mu \mathrm{g} / \mathrm{mL}$, Tukey's post hoc test, $p<0.05$. 


\subsection{Second Derivative Analyses of the Nucleic Acid Spectral Region}

We found significant changes in rat astrocytes treated with $\mathrm{SiO}_{2}-\mathrm{NPs}$ at the spectral bands of $1083 \mathrm{~cm}^{-1}\left(p=0.0177, F_{(5,42)}=3.112\right)$ and $1090 \mathrm{~cm}^{-1}\left(p=0.0211, F_{(5,42)}=2.996\right)$, and in both cases, the lowest signal was observed at $10 \mu \mathrm{g} / \mathrm{mL}$ (Tukey's post hoc test, $p<0.05$, Table 1). A biphasic behavior was observed as $\mathrm{SiO}_{2}-\mathrm{NPs}$ concentration increased (Figure 4a). In contrast, no changes were detected in neurons at the $1083 \mathrm{~cm}^{-1}\left(p=0.595, F_{(5,60)}=0.74\right)$ and $1090 \mathrm{~cm}^{-1}$ bands (Figure $4 \mathrm{~b}, p=0.540$, $\left.F_{(5,60)}=0.8198\right)$.
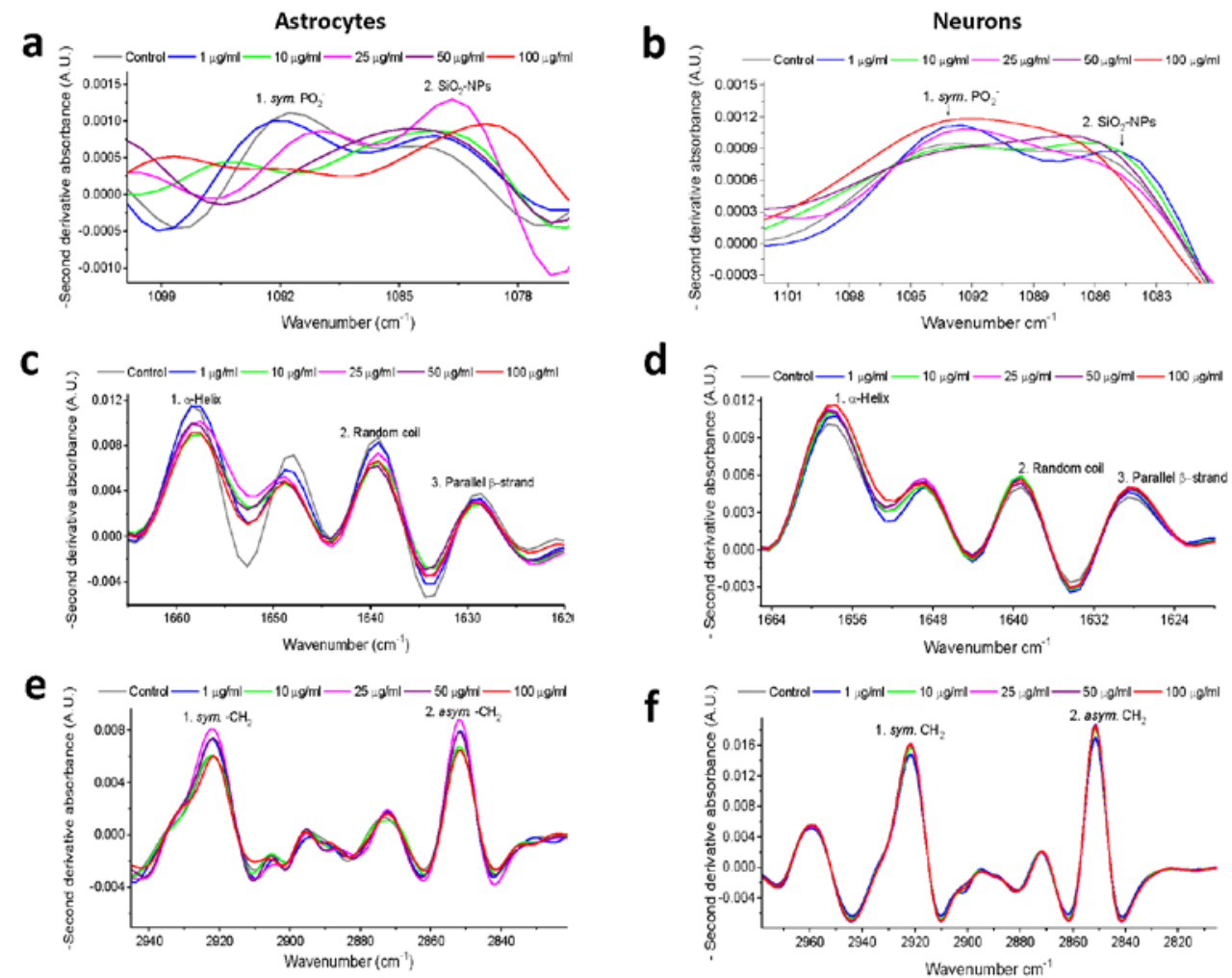

Figure 4. Second derivative spectra analysis of nucleic acids, amide I and lipid regions after $\mathrm{SiO}_{2}-\mathrm{NPs}$ exposure. Nucleic acids correspond to symmetric $\mathrm{PO}_{2}{ }^{-}$at $1090 \mathrm{~cm}^{-1}$, and $\mathrm{SiO}_{2}-\mathrm{NPs}$ correspond to $1083 \mathrm{~cm}^{-1}$ spectral band in (a) astrocytes and (b) neurons. The secondary structure of proteins corresponds to the amide I region, which includes the $1627 \mathrm{~cm}^{-1}$ for parallel $\beta$-strand, $1639 \mathrm{~cm}^{-1}$ for random coil, and $1654 \mathrm{~cm}^{-1}$ for alpha-helix in (c) astrocytes and (d) neurons. Lipids correspond to $1852 \mathrm{~cm}^{-1}$ for symmetric $-\mathrm{CH}_{2}$ and $2923 \mathrm{~cm}^{-1}$ for asymmetric $-\mathrm{CH}_{2}$ in (e) astrocytes and (f) neurons.

\subsection{Second Derivative Analyses of the Protein Spectral Region}

In rat astrocytes, $\mathrm{SiO}_{2}-\mathrm{NPs}$ produced significant differences in spectral bands at $1627 \mathrm{~cm}^{-1}$ $\left(p=0.0167, F_{(5,42)}=3.149\right), 1639 \mathrm{~cm}^{-1}\left(p=0.0241, F_{(5,42)}=2.910\right)$, and $1654 \mathrm{~cm}^{-1}(p=0.0246$, $F_{(5,42)}=2.896$ ), which are related to protein secondary structure (Figure $4 \mathrm{c}$ ). The lowest signal for these spectral bands was observed at $10 \mu \mathrm{g} / \mathrm{mL}$ (Tukey's post hoc test, $p<0.05$, Table 1). In contrast, in neurons, no significant difference in those spectral bands was observed (Figure 4d).

\subsection{Second Derivative Analyses of the Lipid Spectral Region}

In astrocytes exposed to $\mathrm{SiO}_{2}$-NPs, we confirmed the biphasic behavior observed in the normalized IR spectra (Figure 4e), in the spectral band of $2852 \mathrm{~cm}^{-1}$, with the lowest signal detected at $10 \mu \mathrm{g} / \mathrm{mL}$ $\mathrm{SiO}_{2}$-NPs $\left(p=0.0452, F_{(5,42)}=2.503\right)$. In neurons, this spectral band increases with concentration; however, no differences were observed (Figure $4 \mathrm{f}$ ), and it was similar with the spectral band of $2923 \mathrm{~cm}^{-1}$ of asymmetric $-\mathrm{CH}_{2}$, and significant differences were observed in astrocytes $(p=0.0292$, 
$\left.F_{(5,42)}=2.786\right)$, with the lowest peak at the concentration of $10 \mu \mathrm{g} / \mathrm{mL} \mathrm{SiO}_{2}-\mathrm{NPs}(p<0.05$, Table 1$)$. In contrast, there were no observable differences in neurons at the spectral band of $2923 \mathrm{~cm}^{-1}$ under our experimental conditions. At this point, our data suggest a differential sensitivity between astrocytes and neurons to the $\mathrm{SiO}_{2}$-NPs toxicity (Table 1).

\subsection{IQ mapping of Nucleic Acid Region $989-1185 \mathrm{~cm}^{-1}$ in Astrocytes and Neurons after Exposure to $\mathrm{SiO}_{2}-\mathrm{NPS}$}

In order to verify our previous results, IQ mapping was performed. This analysis permits the study of large tissue areas in a free-label manner in both visible and IR mode [24,25]. The spectral signal at $989-1185 \mathrm{~cm}^{-1}$ that included the $\mathrm{SiO}_{2}-\mathrm{NPs}$ and symmetric $\mathrm{PO}_{2}{ }^{-}$of nucleic acid decreased at the concentrations of 1 and $10 \mu \mathrm{g} / \mathrm{mL}$ in astrocytes (Figure S3). The IQ mapping pointed out the low intensity in the spectral signal at the mentioned concentrations, being the lower signal observed at the concentration $10 \mu \mathrm{g} / \mathrm{mL}$ (Figure $5 \mathrm{a}-\mathrm{c}$, blue area). However, at concentrations of $25-100 \mu \mathrm{g} / \mathrm{mL}$, a recovery of the signal was observed; thus, a biphasic effect resulted from $\mathrm{SiO}_{2}-\mathrm{NPs}_{\mathrm{s}}$ in astrocytes as previously observed (Figure $5 \mathrm{~d}-\mathrm{f}$, yellow and red areas). In the case of the neurons (Figure S4 and Figure $5 \mathrm{~g}-1$ ), an increase in the spectral signal in the region $989-1185 \mathrm{~cm}^{-1}$ was observed at the concentration of $1-25 \mu \mathrm{g} / \mathrm{mL}$ (Figure S4 and Figure $5 \mathrm{~g}-\mathrm{j}$, indicated in green and red areas). However, this signal decreased at $50 \mu \mathrm{g} / \mathrm{mL}$ (Figure 5k, yellow area), and at the concentration of $100 \mu \mathrm{g} / \mathrm{mL}$, the lowest signal was detected (Figure 51 , blue area).

\subsection{IQ Mapping of the Protein Amide I Region 1593-1712 $\mathrm{cm}^{-1}$ in Astrocytes and Neurons after Exposure to $\mathrm{SiO}_{2}-\mathrm{NPS}$}

Analysis by IQ mapping of the protein amide I region $1593-1712 \mathrm{~cm}^{-1}$ in rat astrocytes revealed that $\mathrm{SiO}_{2}$-NPs cause a substantial decrease in the intensity of the spectral signal; however, this effect did not follow the linear concentration-response pattern (Figure 6a-f). The most noticeable effect occurs at 1 and $10 \mu \mathrm{g} / \mathrm{mL}$, as indicated in Figure 6b,c (green-blue area). An increase at $25 \mu \mathrm{g} / \mathrm{mL}$ (Figure 6d, yellow area) followed by the decrease at 50-100 $\mu \mathrm{g} / \mathrm{mL}$ (Figure 6e,f, blue area) was observed and resemble the biphasic effect previously observed. In contrast, in neurons, $\mathrm{SiO}_{2}-\mathrm{NPs}$ augmented the spectral signal in the region 1593-1712 $\mathrm{cm}^{-1}$ at concentrations of $10-50 \mu \mathrm{g} / \mathrm{mL}$ (Figure 6i-k, red area). However, at concentration $100 \mu \mathrm{g} / \mathrm{mL} \mathrm{SiO}_{2}$-NPs, the signal decreased (Figure 6l, blue area).

\subsection{IQ Mapping of the Lipid Region 2830-2945 $\mathrm{cm}^{-1}$ in Astrocytes and Neurons after Exposure of $\mathrm{SiO}_{2}-\mathrm{NPs}$}

Analysis by IQ mapping of the region $2830-2945 \mathrm{~cm}^{-1}$ in astrocytes exhibited a decrease in the intensity of the signal in the lipid region that did not follow the linear concentration-response pattern (Figure $7 \mathrm{a}-\mathrm{f}$ ) after exposure to $\mathrm{SiO}_{2}-\mathrm{NPs}$. The most prominent in the spectral area effect occurs at $1-10 \mu \mathrm{g} / \mathrm{mL}$ (Figure $7 \mathrm{~b}$, blue areas), followed by a subtle increase at $25 \mu \mathrm{g} / \mathrm{mL}$ (Figure $7 \mathrm{~d}$, green area) and a second decrease at $50-100 \mu \mathrm{g} / \mathrm{mL}$ (Figure $7 \mathrm{e}, \mathrm{f}$, blue area). The above agrees with the decrease observed in the ATR-FTIR and second derivative analysis. On the other hand, in neurons at $10-25 \mu \mathrm{g} / \mathrm{mL} \mathrm{SiO}_{2}-\mathrm{NPs}$, an increase in the spectral area of the region, $2830-2945 \mathrm{~cm}^{-1}$ was observed (Figure $7 \mathrm{i}, \mathrm{j}$, red area). However, the spectral signal decreased at $50 \mu / \mathrm{mL} \mathrm{SiO}_{2} \mathrm{NPs}_{\text {sith }}$ the lowest signal at $100 \mu \mathrm{g} / \mathrm{mL}$ (Figure 7k,1, yellow, and blue areas, respectively). Collectively, the results from ATR-FTIR spectroscopy and IQ mapping indicated a higher sensitivity of astrocytes to $\mathrm{SiO}_{2}-\mathrm{NPs}$ toxicity than neurons. 

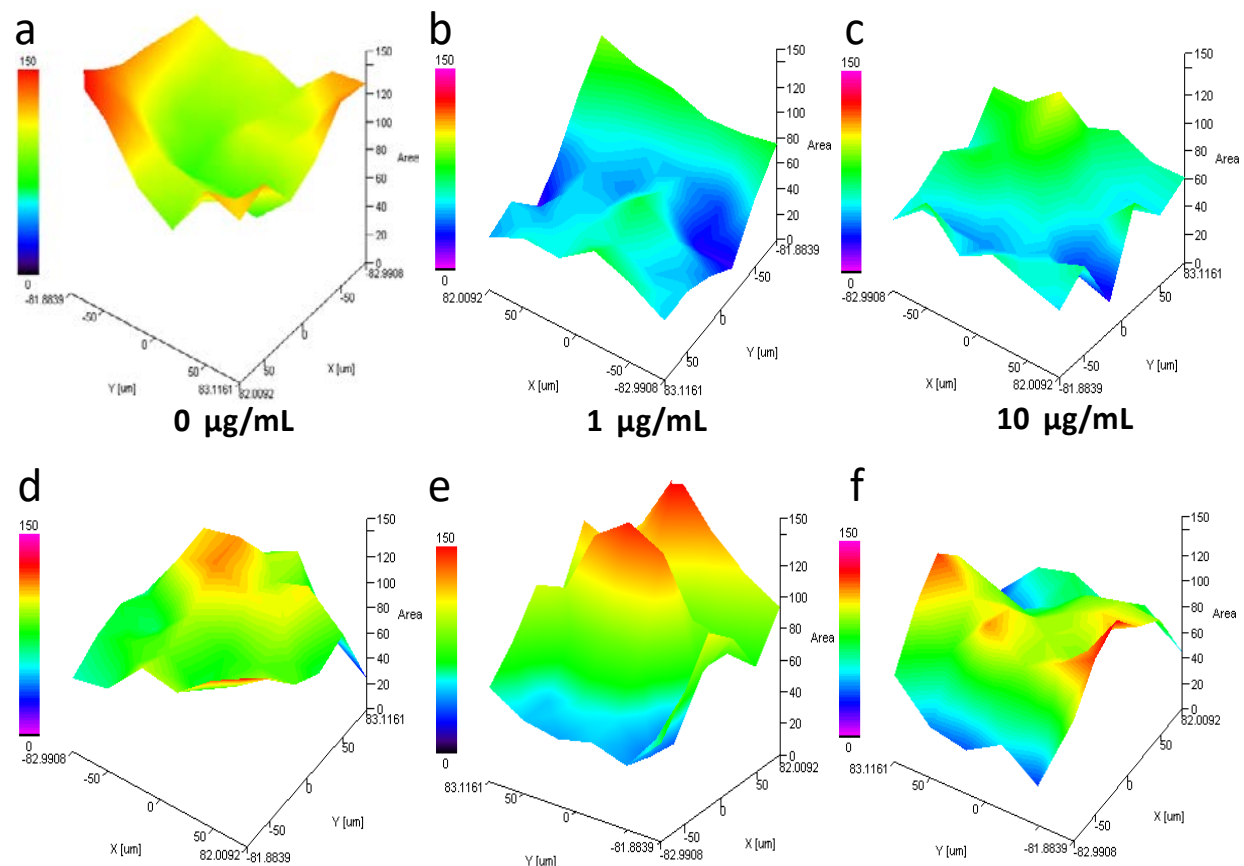

$25 \mu \mathrm{g} / \mathrm{mL}$

$50 \mu \mathrm{g} / \mathrm{mL}$

$100 \mu \mathrm{g} / \mathrm{mL}$

IR spectral area $989-1185 \mathrm{~cm}^{-1}$ Astrocytes
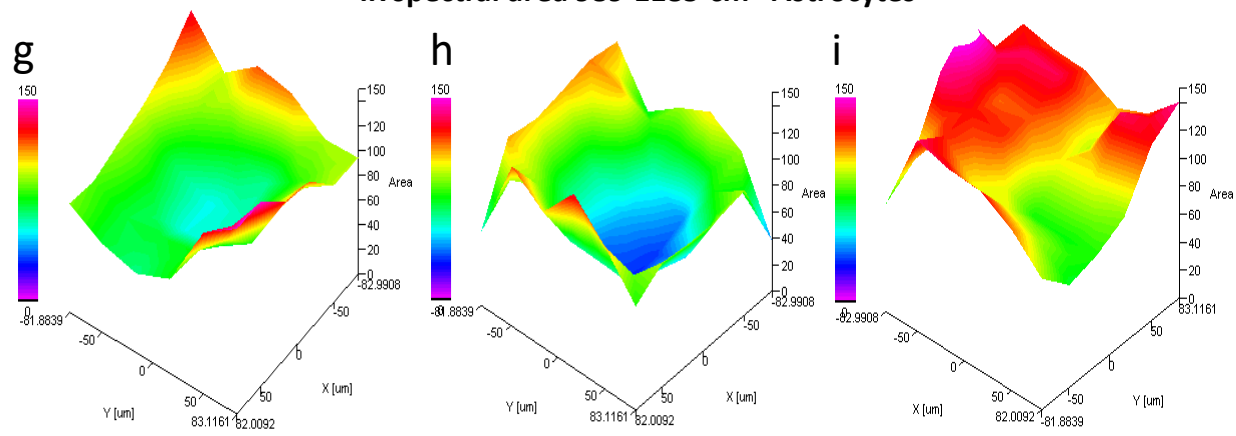

$0 \mu \mathrm{g} / \mathrm{mL}$

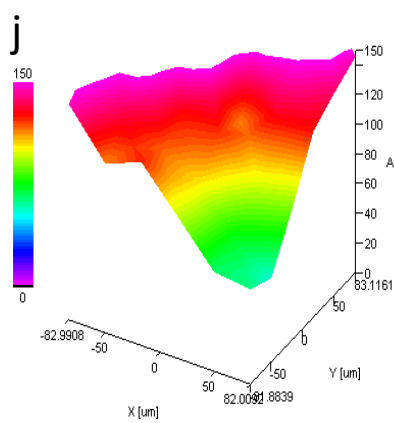

$1 \mu \mathrm{g} / \mathrm{mL}$

$10 \mu \mathrm{g} / \mathrm{mL}$

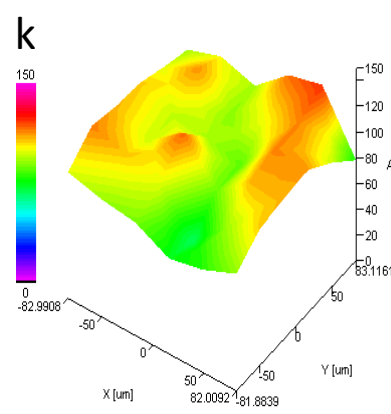

$50 \mu \mathrm{g} / \mathrm{mL}$
I

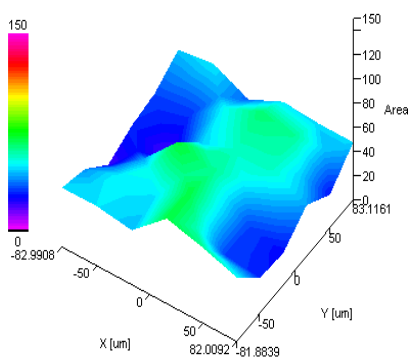

$100 \mu \mathrm{g} / \mathrm{mL}$

\section{IR spectral area $989-1185 \mathrm{~cm}^{-1}$ Neurons}

Figure 5. Spectral area analysis by IQ mapping of $989-1185 \mathrm{~cm}^{-1}$ region of astrocytes and neurons exposed to $\mathrm{SiO}_{2}-\mathrm{NPs}$. The spectral region of $989-1185 \mathrm{~cm}^{-1}$ that includes specific spectral bands related to nucleic acids is presented for astrocytes $(\mathbf{a}-\mathbf{f})$ and neurons $(\mathbf{g}-\mathbf{1})$. A sample of cells treated with $\mathrm{SiO}_{2}-\mathrm{NPs}$ for $24 \mathrm{~h}$ was dispersed on a gold-coated slide. The three-dimensional image is presented in the $x, y$, and $z$ axes, and the area presented as a gradient of color indicates a decrease (from blue) or increase (red) in the spectral signal. For astrocytes, a decrease in the signal was seen at $1 \mu \mathrm{g} / \mathrm{mL}(\mathbf{b})$ and $10 \mu \mathrm{g} / \mathrm{mL}$ (c) $\mathrm{SiO}_{2}-\mathrm{NPs}$ compared to the control (a). Recovery of the signal at $25-100 \mu \mathrm{g} / \mathrm{mL} \mathrm{SiO}_{2}-\mathrm{NPs}$ (d-f) was detected. In neurons, the signal decreased at $1 \mu \mathrm{g} / \mathrm{mL}$ (h) and $100 \mu \mathrm{g} / \mathrm{mL}$ (1); on the contrary, at $10-50 \mu \mathrm{g} / \mathrm{mL}$ (i-k), the signal increased compared to control (g). The image is representative of four independent experiments with three technical replicates. 

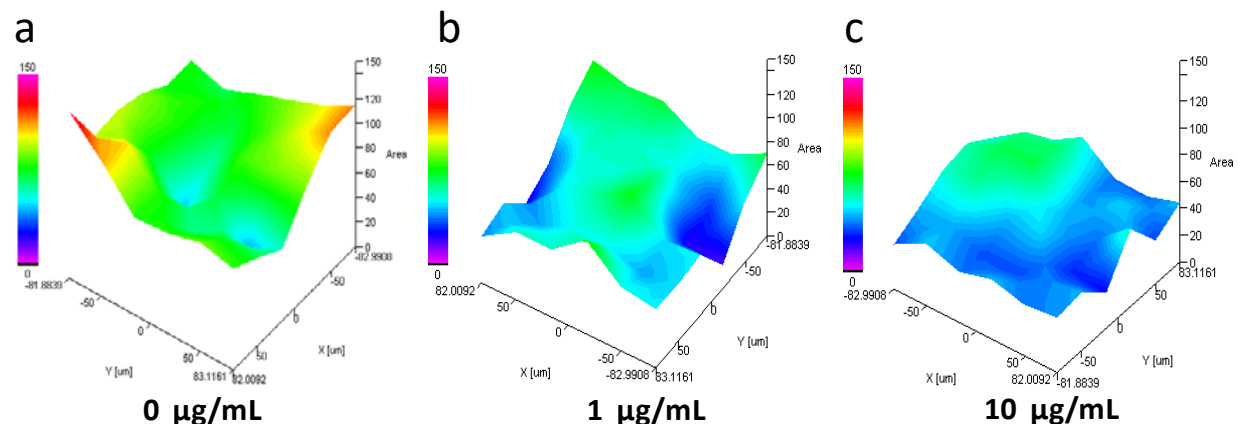

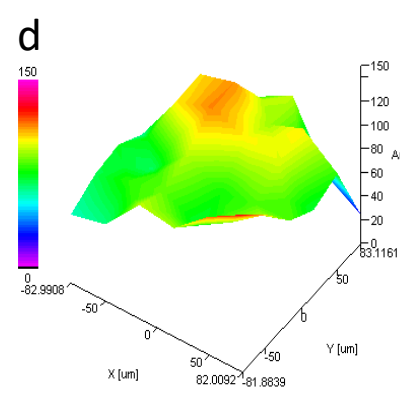

$25 \mu \mathrm{g} / \mathrm{mL}$

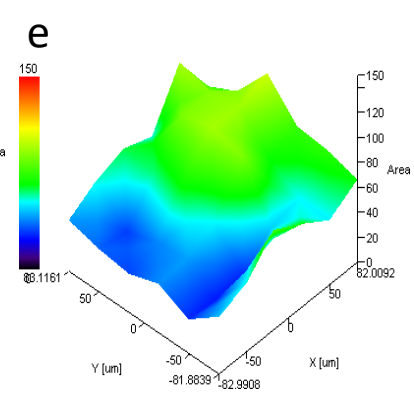

$50 \mu \mathrm{g} / \mathrm{mL}$

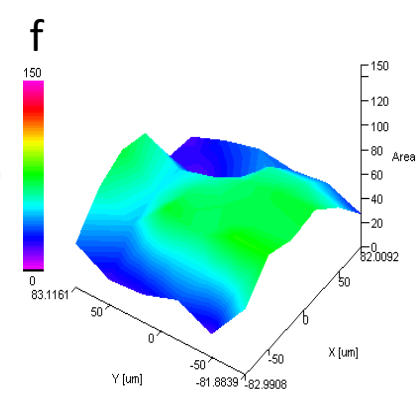

$100 \mu \mathrm{g} / \mathrm{mL}$

IR Spectral area $1593-1712 \mathrm{~cm}^{-1}$ Astrocytes

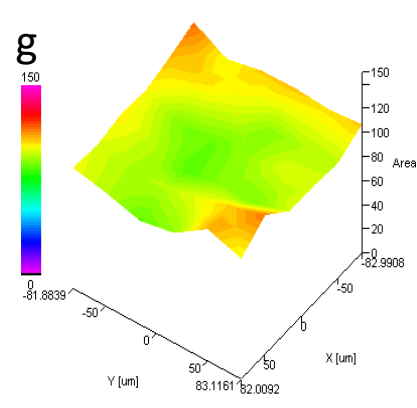

$0 \mu \mathrm{g} / \mathrm{mL}$

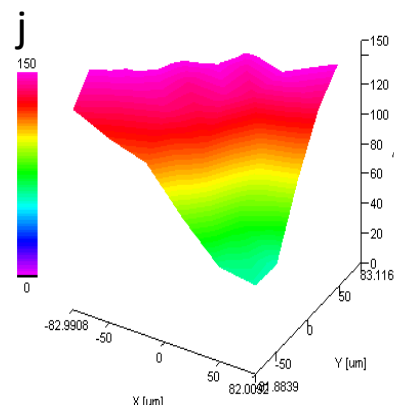

$25 \mu \mathrm{g} / \mathrm{mL}$

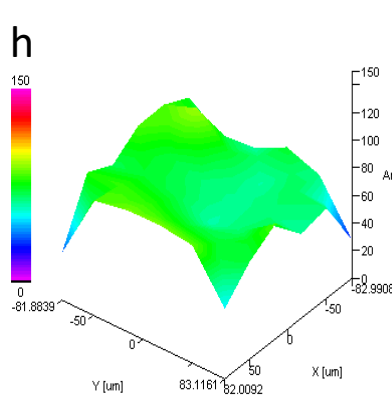

$1 \mu \mathrm{g} / \mathrm{mL}$

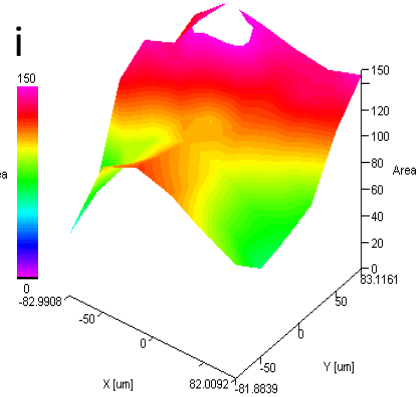

$10 \mu \mathrm{g} / \mathrm{mL}$

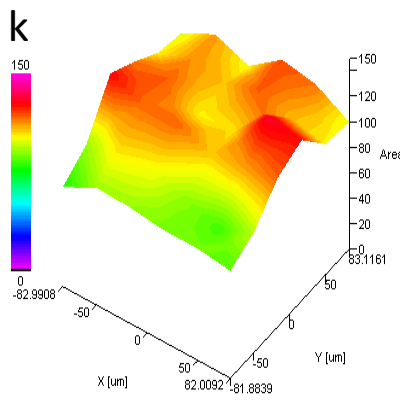

$50 \mu \mathrm{g} / \mathrm{mL}$

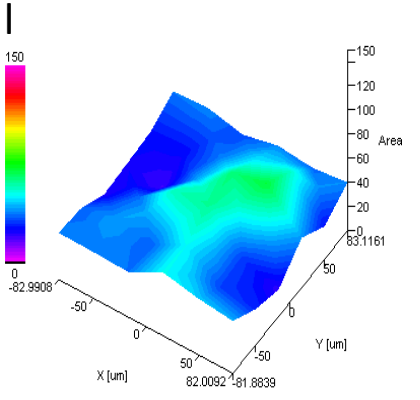

$100 \mu \mathrm{g} / \mathrm{mL}$

IR Spectral area $1593-1712 \mathrm{~cm}^{-1}$ Neurons

Figure 6. Spectral area analysis by IQ mapping of $1593-1712 \mathrm{~cm}^{-1}$ region of astrocytes and neurons exposed to $\mathrm{SiO}_{2}-\mathrm{NPs}$. The spectral region of $1593-1712 \mathrm{~cm}^{-1}$ that includes specific spectral bands related to secondary structures of proteins is presented for astrocytes $(\mathbf{a}-\mathbf{f})$ and neurons $(\mathbf{g}-\mathbf{l})$. A sample of cells treated with $\mathrm{SiO}_{2}$-NPs for $24 \mathrm{~h}$ was dispersed on a gold-coated slide. The three-dimensional image is presented in the $\mathrm{x}, \mathrm{y}$, and $\mathrm{z}$ axes, and the area presented as a gradient of color indicates a decrease (from blue) or increase (red) in the spectral signal. In astrocytes, a decrease in the signal seen as a blue area at 1 (b), 10 (c), 50 (e), and 100 (f) $\mu \mathrm{g} / \mathrm{mL} \mathrm{SiO}_{2}-\mathrm{NPs}$ is observed compared to control (a). No changes were observed at $25 \mu \mathrm{g} / \mathrm{mL}$ (d). In neurons, a strong increase in the signal (red area) was detected at $10(\mathbf{i}), 25(\mathbf{k})$, and $50(\mathbf{l}) \mu \mathrm{g} / \mathrm{mL}$. In contrast, at concentration of 1 (h) and $100(\mathbf{l}) \mu \mathrm{g} / \mathrm{mL}$, spectral signal decrease (green and blue area) when compared to control (g). The image is representative of four independent experiments with three technical replicates. 

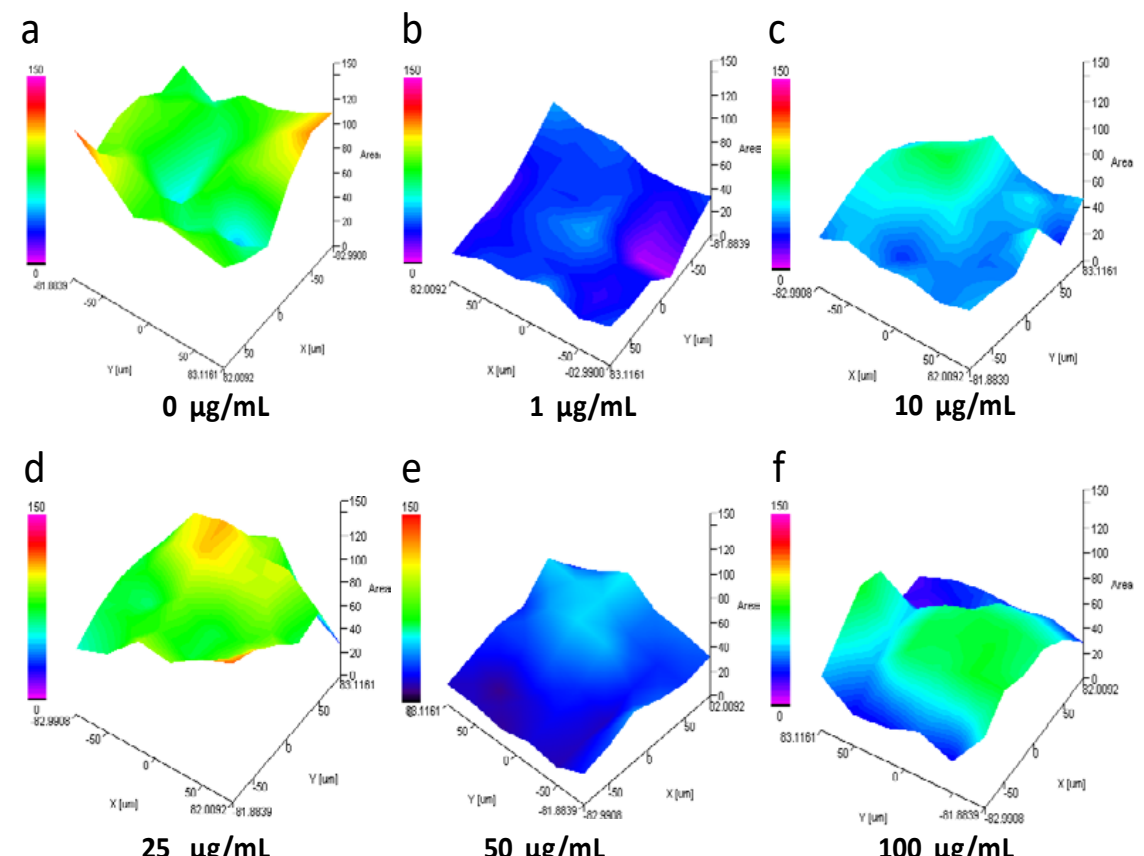

$25 \mu \mathrm{g} / \mathrm{mL}$

$50 \mu \mathrm{g} / \mathrm{mL}$

$100 \mu \mathrm{g} / \mathrm{mL}$

IR Spectral area $2830-2945 \mathrm{~cm}^{-1}$ Astrocytes
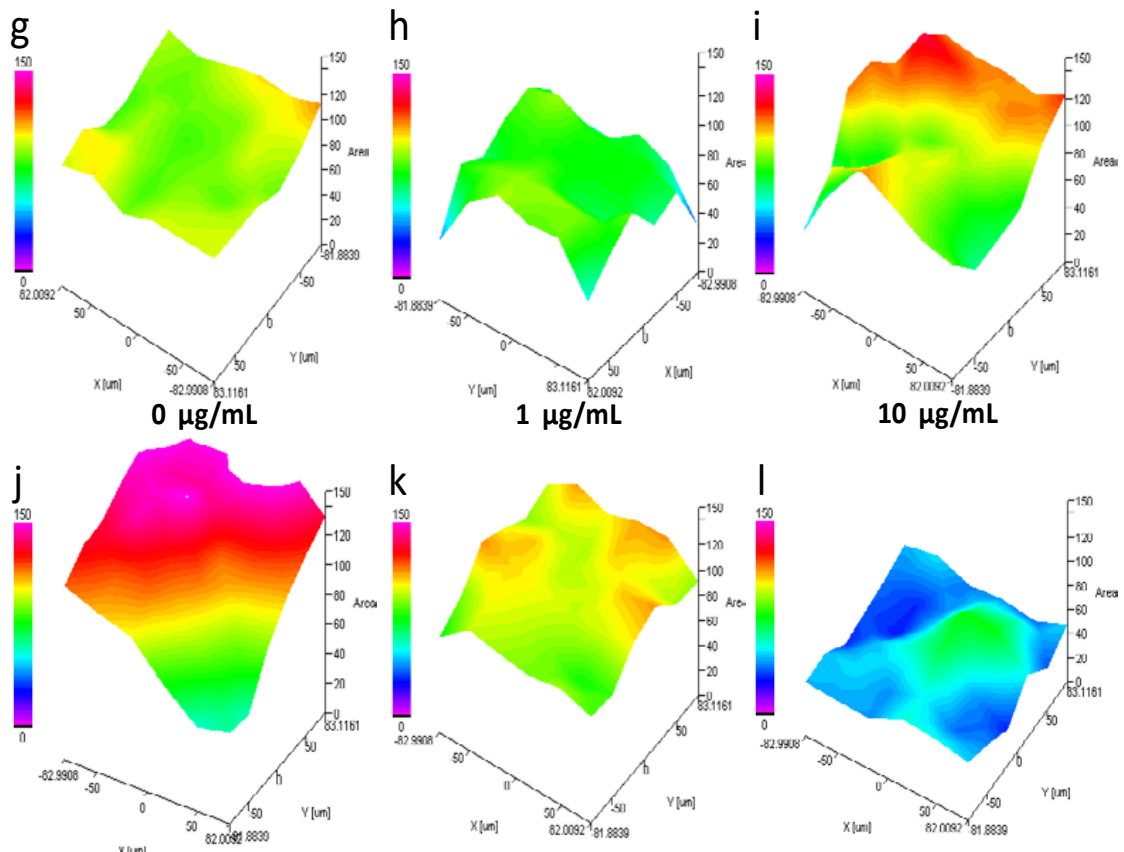

$25 \mu \mathrm{g} / \mathrm{mL}$

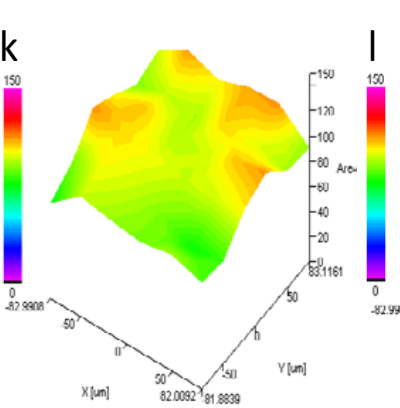

$50 \mu \mathrm{g} / \mathrm{mL}$

IR Spectral area $2830-2945 \mathrm{~cm}^{-1}$ Neurons

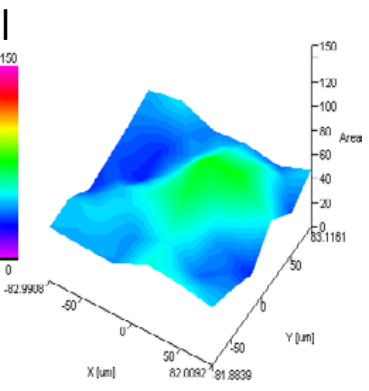

$100 \mu \mathrm{g} / \mathrm{mL}$

Figure 7. IQ mapping of IR spectral region $2830-2945 \mathrm{~cm}^{-1}$ of astrocytes and neurons exposed to $\mathrm{SiO}_{2}$-NPs. The spectral region of $2830-2945 \mathrm{~cm}^{-1}$ that includes specific spectral bands of symmetric and asymmetric vibrations of $-\mathrm{CH}_{2}$ of lipids is presented for astrocytes $(\mathbf{a}-\mathbf{f})$ and neurons $(\mathbf{g}-\mathbf{1})$. A sample of cells treated with $\mathrm{SiO}_{2}-\mathrm{NPs}$ for $24 \mathrm{~h}$ was dispersed on a gold-coated slide. The three-dimensional image is presented in the $\mathrm{x}, \mathrm{y}$, and $\mathrm{z}$ axes, and the area presented as a gradient of color indicates a decrease (from blue) or increase (red) in the spectral signal. In astrocytes (a-f), a decrease in the signal (blue area) occurred at 1 (b), 10 (c), 50 (e), and 100 (f) $\mu \mathrm{g} / \mathrm{mL}$ of $\mathrm{SiO}_{2}-\mathrm{NPs}$ when compared to control (a). No changes were observed at $25 \mu \mathrm{g} / \mathrm{mL}$ (d). In neurons (g-1), spectral signal increased (red area) from 1-50 $\mu \mathrm{g} / \mathrm{mL}$ (h-k) when compared to control (g). The higher increase in signal was detected at $25 \mu \mathrm{g} / \mathrm{mL}$ (j). On the contrary, at the concentration of $100 \mu \mathrm{g} / \mathrm{mL}(\mathbf{l})$, the lowest spectral signal was detected. The image is representative of four independent experiments with three technical replicates. 


\subsection{Cell Viability Determination}

In order to verify the FTIR spectroscopic analysis, we evaluated the effect of $\mathrm{SiO}_{2}-\mathrm{NPs}_{\text {s }}$ on the cell viability in astrocytes and neurons. The effect of $\mathrm{SiO}_{2}-\mathrm{NPs}$ on the viability evaluated by the calcein-AM uptake assay in astrocytes and neurons resulted in a decrease of 33.4\% in the uptake of calcein-AM in astrocytes at a concentration of $10 \mu \mathrm{g} / \mathrm{mL}, 46.2 \%$ at $50 \mu \mathrm{g} / \mathrm{mL}$, and $63.3 \%$ at $100 \mu \mathrm{g} / \mathrm{mL}$. In neurons, a significant decrease of $41.4 \%$ at $50 \mu \mathrm{g} / \mathrm{mL}$ and $52.2 \%$ at $100 \mu \mathrm{g} / \mathrm{mL}$ was detected (Figure $8 \mathrm{a}$ ). Astrocytes showed a significant decrease in cell viability at a lower concentration than neurons $(10 \mu \mathrm{g} / \mathrm{mL})$, and the significance of the decreases was always higher in astrocytes than those detected in neurons. Therefore, these results confirmed the toxic effects of $\mathrm{SiO}_{2}-\mathrm{NPs}$ on astrocytes and neurons described before and pinpoint the major susceptibility of astrocytes to the toxic effect of $\mathrm{SiO}_{2}-\mathrm{NPs}$ compared to neurons. However, as was previously reported [26], the MTT reduction assay was not useful to estimate the cell death, since we did not detect significant changes (Figure 8b).

a

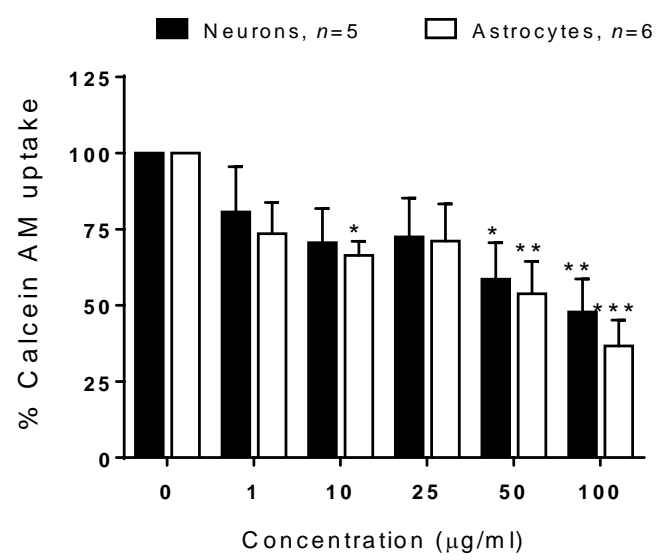

b

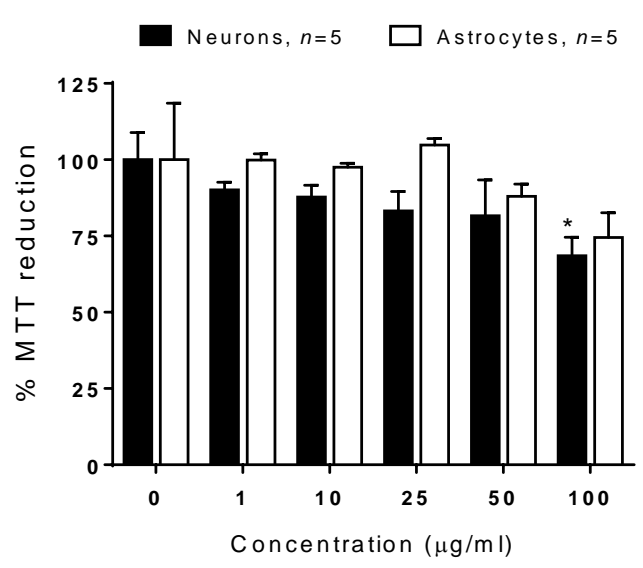

Figure 8. Viability of astrocytes and neurons after exposure to $\mathrm{SiO}_{2}-\mathrm{NPs}$. The neurons and astrocytes were exposed to $0-100 \mu \mathrm{g} / \mathrm{mL} \mathrm{SiO}_{2}$-NPs. (a) Calcein-AM uptake in neurons and astrocytes. (b) MTT reduction in neurons and astrocytes. Data are presented as mean \pm SEM of five to six independent experiments with three technical replicates. Statistical analysis was by two-way ANOVA followed by Bonferroni's post hoc test. ${ }^{*} p<0.05,{ }^{* *} p<0.01,{ }^{* * *} p<0.001$ vs. control.

\section{Discussion}

In the present study, the toxic effect of $\mathrm{SiO}_{2}$-NPs on primary cultures of rat astrocytes and neurons was evaluated by ATR-FTIR spectroscopy and IQ mapping; results showed a higher sensitivity of astrocytes than neurons. The higher susceptibility in astrocytes was evidenced by disturbances in cell morphology and changes in biomolecules, mainly proteins. The adverse effect was associated with changes in biomolecules such as nucleic acids, proteins, and lipids, detectable through alterations in the absorption of specific spectral bands. The principal mechanism of toxicity was related to alterations in secondary structures of proteins in astrocytes. The cell viability test confirmed a higher sensitivity of astrocytes than neurons, and the toxic effect of $\mathrm{SiO}_{2}-\mathrm{NPs}$ was detected since low concentrations.

We obtained spectral bands of pure powder $\mathrm{SiO}_{2}-\mathrm{NPs}$ similar to those reported by Marfin et al. [27]. However, the spectral position of bands of $\mathrm{SiO}_{2}-\mathrm{NPs}$ dispersed in cell culture media was slightly different in the vibrations $\mathrm{Si}-\mathrm{O}$ out of plane deformation, $\mathrm{Si}-\mathrm{OH}$ stretching, and $\mathrm{Si}-\mathrm{O}-\mathrm{Si}$ asymmetric stretching. A shift in peak position usually means electron redistribution in the molecular bonds; thus, hydrogen bonding interferences after $\mathrm{SiO}_{2}$-NPs dispersion in saline could be a plausible explanation for the shift observed in the peak position. For example, variations in the value of a spectral band have been previously reported in cell culture and could be attributed to residual water present in the sample [28]. 
Concerning the $\mathrm{SiO}_{2}$-NPs physical form, we found an amorphous shape and a size below 100 $\mathrm{nm}$; the hydrodynamic size of $\mathrm{SiO}_{2}-\mathrm{NPs}$ was high because, generally, NPs agglomerates in liquid media. This agglomeration is a crucial aspect of $\mathrm{SiO}_{2}-\mathrm{NPs}$ because their toxic effect depends on size and charge. These two properties are related to the passage of NPs through biological barriers to allocate in the intracellular space and consequently to produce the toxic effect, as was demonstrated with $\mathrm{SiO}_{2}$-NPs of $70 \mathrm{~nm}$ in a model of intravenous exposure during pregnancy in a mouse model. In that work, the authors found that $\mathrm{SiO}_{2}-\mathrm{NP}$ cross biological barriers and cause alterations in the placenta and damage to the liver and brain in the fetuses [7]. In another example, Kim et al. [29] reported that different sized and charged $\mathrm{SiO}_{2}-\mathrm{NPs}$ would cause differential immunotoxicity, being the small-sized and negatively charged $\mathrm{SiO}_{2}-\mathrm{NPs}$ the most potent immunotoxic NPs. Usually, suspension of any type NPs creates agglomeration, which is bigger than the original size of individual NPs in the dry state. This agglomeration is formed by chemical and/or physical interactions between NPs and the liquid dispersion medium components. Izak-Nau et al. [30] demonstrated that $\mathrm{SiO}_{2}-\mathrm{NPs}$ have spherical form, are core-shell, and are sized $50 \mathrm{~nm}$; they form clusters that remained adsorbed on the surface in cultured astrocytes, followed by a modest absorption. Moreover, the agglomerates or clusters can be internalized and frequently are maintained in vesicles. In some cases, the size of agglomerates in vesicles might be bigger than the cluster before the cell uptake, as has been well demonstrated. For instance, $\mathrm{SiO}_{2}$-NPs sized $90 \mathrm{~nm}$ showed an agglomeration state of $150 \mathrm{~nm}$ in water solution. However, clusters of $\mathrm{SiO}_{2}$-NPs from 500 to $1000 \mathrm{~nm}$ were detected in vesicles of neural stem cells exposed for $48 \mathrm{~h}$ [31]. Clusters of $\mathrm{SiO}_{2}-\mathrm{NPs}$ have been recently detected in endolysosomes of primary cultures of hippocampal neurons from Wistar rats [32]. Importantly, the $\mathrm{SiO}_{2}-\mathrm{NPs}$ uptake in these hippocampal neurons was accompanied by an increase in beta-amyloid levels, which highlights that $\mathrm{SiO}_{2}$-NPs internalization might have an impact on some neurodegenerative diseases such as Alzheimer disease.

In our study, there is evidence that the incorporation of the NPs did occur. Uptake of $\mathrm{SiO}_{2}-\mathrm{NPs}$ could be assumed based on the spectral band of $1083 \mathrm{~cm}^{-1}$ that corresponds to the most representative band for $\mathrm{SiO}_{2}$-NPs with the FTIR analysis. The absorbance of this band increased at all concentrations of $\mathrm{SiO}_{2}-\mathrm{NPs}$ in astrocytes without a change in the control group. We interpreted this as evidence of the uptake of $\mathrm{SiO}_{2}-\mathrm{NPs}$ by astrocytes. Nonetheless, no changes were detected in neurons when we analyzed the same spectral band in the second derivative analysis. Beyond this evidence, the cell uptake of $\mathrm{SiO}_{2}-\mathrm{NPs}$ has been well demonstrated in cell cultures of neural stem cells and hippocampal neurons, but also in other non-brain cell lineages including macrophages [33], intestinal epithelial cell line C2BBe1 [34], keratinocytes [35] and hepatocytes [36].

Namely, $\mathrm{SiO}_{2}$-NPs formed agglomerates, and this is a crucial observation because cells can uptake $\mathrm{SiO}_{2}$-NPs agglomerates through endocytosis. We must underline that astrocytes and microglia have the phagocytic capacity [37-39], and NPs endocytosis has been described mostly in neurons [32]. Once inside the cytoplasm, NPs induce cellular death, as has been demonstrated in vivo and in vitro $[8,40]$.

Moreover, agglomerates of $\mathrm{SiO}_{2}-\mathrm{NPs}$ around $150-200 \mathrm{~nm}$ have been detected in primary microglia, and the incorporation is related to phagocytosis. Inside the cell, $\mathrm{SiO}_{2}-\mathrm{NPs}$ may alter microglial function by the increase of ROS and nitrogen oxidative species production, deregulation of pro-inflammatory genes, and cytokine release [41]. As astrocytes are endocytic cells too [42], it is feasible that $\mathrm{SiO}_{2}$-NPs incorporation in rat astrocytes and neurons occurred through phagocytosis and endocytosis in the current study. Moreover, as phagocytosis is a highly active mechanism in astrocytes, this could contribute to their higher sensitivity to $\mathrm{SiO}_{2}$-NPs toxicity than those observed in neurons. Furthermore, as astrocytes cooperate with neurons at various levels, including trafficking and recycling of neurotransmitters, ionic homeostasis, energy metabolism, and the defense against oxidative stress, any alteration in their function would have a significant impact on the brain. As an example of the effect of NPs on astrocytic function, titanium dioxide NPs induced a significant loss in glutamate uptake associated with mechanisms involved in cell death, like the production of reactive oxygen species and mitochondrial dysfunction [43]. As the glutamate uptake is a fundamental function of 
astrocytes to avoid excitotoxicity and to provide glutamine to neurons, the nanoparticle exposition could impair synaptic transmission and promote neuronal death. A subject of special attention is the blood-brain barrier (BBB), whose integrity is essential to regulate the movement of molecules between blood and brain. Some reports have revealed significant effects of NPs on BBB integrity. For example, the exposition to silver NPs triggers the increase of permeability in an in vitro model of BBB [44]. In order to understand the effects of $\mathrm{SiO}_{2}-\mathrm{NPs}$ on the modulation of the synaptic transmission in neurons, the effect of $\mathrm{SiO}_{2}-\mathrm{NPs}$ on co-cultures of neurons and astrocytes should be evaluated. Moreover, $\mathrm{SiO}_{2}-\mathrm{NPs}$ interrupted the tight junctions and generated changes in the cytoskeleton in endothelial cells through an IL-6 and VEGF-mediated inflammatory response coordinated with astrocytes [11]. The cytoskeleton alterations reported in the literature and our findings from FTIR spectroscopy about alterations in the secondary structure of proteins encourage us to continue exploring the mechanisms of toxicity and uptake of $\mathrm{SIO}_{2}$-NPs in vitro shortly, through the co-culturing of neural and glial cells, infrared spectroscopy, microscopy, and molecular biology.

Regarding the morphological changes observed in astrocytes and neurons, the presence of intracellular NPs would trigger alterations in protein synthesis evidenced through the changes in the absorbance of the protein spectral region observed. In spite that this study was not specifically designed to study the morphological changes in astrocytes and neurons deeply, we realized small morphological changes at low concentrations of $\mathrm{SiO}_{2}-\mathrm{NPs}$ in both cell types and prominent alterations in astrocytes size, cell volume, and loss of branch at the highest concentrations. The above agrees with previous work about morphological changes described in HL-7702 cells after exposure to $\mathrm{SiO}_{2}-\mathrm{NPs}_{\text {for }} 24 \mathrm{~h}$, where cell volume decreased, together with the presence of cytoplasm and nuclear vacuoles, dense cytoplasm, and formation of apoptotic bodies. At the concentration of $200 \mu \mathrm{g} / \mathrm{mL}$, apoptosis was detected as nuclear membrane thickening, cell body shrinkage, nuclear pyknosis, and disintegration [45]. In the present study, we observed a biphasic response in astrocytes and neurons after exposure to $\mathrm{SiO}_{2}-\mathrm{NPs}_{\text {. }}$ This biphasic behavior has been previously observed with other NPs at low concentrations [46]. For example, in human skin fibroblasts in culture, $0.5 \mu \mathrm{g} / \mathrm{mL} \mathrm{SiO}_{2}-\mathrm{NPs}$ have a beneficial effect through improved survival and function of the cells, meanwhile, at $50 \mu \mathrm{g} / \mathrm{mL}$ or higher, a clear increase of cell death was detected [47]. Although specific molecular mechanisms remain to be fully understood, biphasic responses detected in this study to $\mathrm{SiO}_{2}-\mathrm{NPs}$ support the previous hypothesis in the field, where it has been proposed that biphasic responses could be considered as an emergent physicochemical property of nanoparticles, especially at low concentrations. However, time and environmental exposure scenarios must be included in future studies, as previously reported [46,47].

The alterations detected in spectral regions of nucleic acids, protein, and lipids in astrocytes and neurons are compatible with mechanisms of $\mathrm{SiO}_{2}-\mathrm{NPs}$ toxicity previously reported for other cell types, such as ROS production, lipid oxidation, protein misfolding or reduced synthesis, and cell death by autophagy [48]. These mechanisms have been observed in vitro [48-50] and in vivo [8,50] studies. Indeed, morphological changes observed in astrocytes and neurons exposed to $\mathrm{SiO}_{2}-\mathrm{NPs}_{\text {, }}$ even at the low concentrations of 1 and $10 \mu \mathrm{g} / \mathrm{mL}$, may be explained by the ability of $\mathrm{SiO}_{2}-\mathrm{NPs}$ to disrupt proteins, as observed by the changes in the spectral signal of specific bands related to the secondary structure of proteins. In this regard, previous proteomic analysis has evidenced a large number of proteins associated with the cytoskeleton and crucial cellular functions oxidative stress, energy metabolism, apoptosis, among others, disrupted by $\mathrm{SiO}_{2}-\mathrm{NPs}$ [51]. Moreover, silicon materials produce ROS by the interaction between $\mathrm{Si}$ and $\mathrm{O}_{2} \bullet$ - such as $\mathrm{SiO} \bullet, \mathrm{SiO}_{2} \bullet, \mathrm{SiO}_{3} \bullet$ [50], and considering that unlike neurons, astrocytes contain free most of the complex I and higher ROS production [52], an intracellular oxidant environment could be formed, resulting in more significant damage to DNA and proteins and consequently cell death, as seen for astrocytes in our study.

The decrease in the spectral signal related to the amide I and secondary structures of proteins could be interpreted as a lack of bond formation as a consequence of the protein synthesis decrease or a misfolding of proteins. At similar concentrations, Yang et al. [53] showed that treatment with $10 \mu \mathrm{g} / \mathrm{mL}$ $\mathrm{SiO}_{2}$-NPs sized $15 \mathrm{~nm}$ for $24 \mathrm{~h}$, induces altered expression of amyloid precursor protein (APP) and 
neprilysin, enhances phosphorylation of tau, and activates the glycogen synthase kinase (GSK)-3 $\beta$ in human SK-N-SH and rodent neuroblastoma cells. These alterations are related to pathological signs of Alzheimer's disease; thus, it is likely that neurofilaments and glial filaments have been modified after exposure to $\mathrm{SiO}_{2}$-NPs. Additionally, secondary structures of neurofilaments and glial filaments are mainly composed of alpha-helices, and after interaction between ROS and the peptide backbone, those helices could be partly modified into beta-sheet and random coil structures [54]. Hence, the alterations in the secondary structures observed in astrocytes and neurons may be interpreted as a reorganization of the glial filament and neurofilament structure after interaction with ROS formed as a consequence of $\mathrm{SiO}_{2}-\mathrm{NPs}$ exposure. The above is a plausible explanation for the astrocytic and neuronal degeneration observed after exposure to $\mathrm{SiO}_{2}$-NPs in this study.

Although the increase in the absorbance of spectral bands related to lipids due to $\mathrm{SiO}_{2}-\mathrm{NPs}$ was not statistically different in neurons, it cannot rule out that $\mathrm{SiO}_{2}-\mathrm{NPs}$ has a deleterious effect in the lipid membrane promoting neuronal death at higher concentrations as in the case of astrocytes. Meanwhile, autophagy could be involved in astrocytes' cell death; it is possible that in neurons, apoptosis/necrosis could be the mechanism of cell death implied. The above is supported by the increase in absorbance at $2852 \mathrm{~cm}^{-1}$ and $2923 \mathrm{~cm}^{-1}$ observed in this study, which agrees with an increase in the same spectral bands reported in U937 and CCRF-CEM cells that underwent to apoptosis/necrosis after several acute stress conditions and were studied by FTIR spectroscopy [22]. In contrast, PC12 cells exposed directly to $\mathrm{SiO}_{2}-\mathrm{NPs}$ size $25 \mathrm{~nm}$ at $25-200 \mu \mathrm{g} / \mathrm{mL}$ for $24 \mathrm{~h}$, increased NPs uptake, and autophagy in a concentration-dependent way [55]. These discrepancies highlight the need for more studies to explain the mechanisms and factors involved in neural death after acute exposure to $\mathrm{SiO}_{2}-\mathrm{NPs}$.

Finally, we found that ATR-FTIR spectroscopy together with IQ mapping was useful to evaluate the toxic effect of $\mathrm{SiO}_{2}$-NPs and also allowed the study of the molecular fingerprint after exposure to NPs avoiding the need of reagents or complicated manipulation of the samples [14,22]. However, one of the limitations of the FTIR analysis is that we cannot distinguish the groups of affected proteins, but this technique performed a rapid screening of cell status after exposure to toxic substances. Moreover, the second derivative analysis enabled the elucidation of the mechanisms involved in the decrease of viability after exposure to the NPs. The cell viability test based on Calcein-AM uptake was an excellent tool to evaluate cell viability and confirmed the higher susceptibility of astrocytes to the toxic effect of $\mathrm{SiO}_{2}$-NPs compared to neurons, but MTT reduction was not the best way to evaluate cell viability of astrocytes. The above observation agrees with a previous report that discourages the use of MTT to evaluate nanoparticle toxicity [26] since mesoporous silicon NPs stimulate the formazan exocytosis, rendering an overestimation of the cytotoxicity. In spite that we found the contrary effect, ergo an underestimation of cytotoxicity using MTT reduction, our results using $\mathrm{SiO}_{2}-\mathrm{NPs}$ that are not mesoporous confirmed that MTT reduction should not be used for silicon nanoparticle cytotoxicity evaluation. The above could be related with the mainly glycolytic metabolism that is present in astrocytes. MTT reduction is a method based on the enzymatic activity of cell dehydrogenases like lactate dehydrogenase (which converts pyruvate to lactate) or succinate dehydrogenase (an enzyme from oxidative metabolism).

In conclusion, our data show that primary cultures of astrocytes displayed higher sensitivity than neurons to $\mathrm{SiO}_{2}-\mathrm{NPs}$ toxicity, evidenced through morphological changes, alterations in the IR spectral signal of nucleic acids, lipids, and proteins. The main mechanisms involved in the toxicity of $\mathrm{SiO}_{2}$-NPs, specifically for astrocytes, involves alterations in the secondary structure of proteins. However, additional studies are necessary to deepen the knowledge about neurons and astrocytes susceptibility to toxic stimuli. Moreover, complementary studies exploring the effects of $\mathrm{SiO}_{2}-\mathrm{NPs}$ to evaluate the interaction between glia and neurons could be performed to enlarge the precise mechanism involved in cell death. 
Supplementary Materials: The following are available online at http://www.mdpi.com/2305-6304/8/3/51/s1, Table S1: Spectral bands $\left(\mathrm{cm}^{-1}\right)$ of chemical bonds of biomolecules detected by ATR-FTIR Spectroscopy in rat astrocytes and neurons exposed to $\mathrm{SiO}_{2}-\mathrm{NPs}$; Figure S1. Identification of cell cultures; Figure S2. A spectral fingerprint of rat astrocytes and neurons exposed to $\mathrm{SiO}_{2}-\mathrm{NPs}$; Figure S3. FTIR microscopy and IQ mapping analysis of the spectral region of $989-1185 \mathrm{~cm}^{-1}$ of astrocytes exposed to $\mathrm{SiO}_{2}-\mathrm{NPs}$; Figure S4. FTIR microscopy and IQ mapping analysis of the spectral region of $989-1185 \mathrm{~cm}^{-1}$ of astrocytes exposed to $\mathrm{SiO}_{2}-\mathrm{NPs}$. FTIR microscopy analysis and IQ mapping of neurons exposed to $\mathrm{SiO}_{2}-\mathrm{NPs}$.

Author Contributions: Conceptualization, J.H.L.-P., Y.I.C. and M.O.-I.; formal analysis, J.H.L.-P., N.J.-B., A.M.-C., M.M.M.-M., G.J.V.-Z., and M.O.-I.; funding acquisition, J.P.-C. and Y.I.C.; investigation, J.H.L.-P., N.J.-B., A.D.-A., and M.O.-I.; resources, M.M.M.-M., G.J.V.-Z., J.P.-C., Y.I.C., and M.O.-I.; supervision, Y.I.C. and M.O.-I.; visualization, J.H.L.-P., A.M.-C., and M.O.-I.; writing-original draft, J.H.L.-P. and M.O.-I.; writing—review and editing, A.D.-A., J.P.-C., and Y.I.C. All authors have read and agreed to the published version of the manuscript.

Funding: This research was funded by the Universidad Nacional Autónoma de Mexico, grant numbers 5000-9105 to J.P.-C. and IN224119 to Y.I.C., and the Consejo Nacional de Ciencia y Tecnología, Mexico, grant number 268769 to Y.I.C.

Acknowledgments: Thanks to MSc. Miguel Sánchez Brito for the development of an algorithm used in the analysis of the ATR-FTIR spectra and to M.C. Mayor Emanuel Noriega at the Research Unit at the EMM for his technical support. Alejandro Déciga-Alcaraz is a doctoral student from the Programa de Doctorado en Ciencias Biomédicas, Universidad Nacional Autónoma de Mexico (UNAM), and received the fellowship 582547 from the Consejo Nacional de Ciencia y Tecnología, Mexico.

Conflicts of Interest: The authors declare no conflict of interest. The funders had no role in the design of the study; in the collection, analyses, or interpretation of data; in the writing of the manuscript; or in the decision to publish the results.

\section{References}

1. Dekkers, S.; Krystek, P.; Peters, R.J.; Lankveld, D.P.; Bokkers, B.G.; van Hoeven-Arentzen, P.H.; Bouwmeester, H.; Oomen, A.G. Presence and risks of nanosilica in food products. Nanotoxicology 2011, 5, 393-405. [CrossRef]

2. Younes, M.; Aggett, P.; Aguilar, F.; Crebelli, R.; Dusemund, B.; Filipic, M. Re-evaluation of silicon dioxide (E 551) as a food additive. EFSA J. 2018, 16, e05088. [CrossRef]

3. Napierska, D.; Thomassen, L.C.J.; Lison, D.; Martens, J.A.; Hoet, P.H. The nanosilica hazard: Another variable entity. Part. Fibre Toxicol. 2010, 7, 39. [CrossRef] [PubMed]

4. Turci, F.; Pavan, C.; Leinardi, R.; Tomatis, M.; Pastero, L.; Garry, D. Revisiting the paradigm of silica pathogenicity with synthetic quartz crystals: The role of crystallinity and surface disorder. Part. Fibre Toxicol. 2016, 13, 32. [CrossRef] [PubMed]

5. Murugadoss, S.; Lison, D.; Godderis, L.; Van den Brule, S.; Mast, J.; Brassinne, F. Toxicology of silica nanoparticles: An update. Arch Toxicol. 2017, 91, 2967-3010. [CrossRef] [PubMed]

6. Du, Z.J.; Chen, S.Y.; Cui, G.Q.; Yang, Y.; Zhang, E.G.; Wang, Q. Silica nanoparticles induce cardiomyocyte apoptosis via the mitochondrial pathway in rats following intratracheal instillation. Int. J. Mol. Med. 2019, 43, 1229-1240. [CrossRef] [PubMed]

7. Yamashita, K.; Yoshioka, Y.; Higashisaka, K.; Mimura, K.; Morishita, Y.; Nozaki, M. Silica and titanium dioxide nanoparticles cause pregnancy complications in mice. Nat. Nanotechnol. 2011, 6, 321-328. [CrossRef]

8. Wu, J.; Wang, C.; Sun, J.; Xue, Y. Neurotoxicity of Silica Nanoparticles: Brain Localization and Dopaminergic Neurons Damage Pathways. ACS Nano 2011, 5, 4476-4489. [CrossRef]

9. Parveen, A.; Rizvi, S.H.M.; Mahdi, F.; Tripathi, S.; Ahmad, I.; Shukla, R.K. Silica nanoparticles mediated neuronal cell death in corpus striatum of rat brain: Implication of mitochondrial, endoplasmic reticulum and oxidative stress. J. Nanopart. Res. 2014, 16, 2664. [CrossRef]

10. Parveen, A.; Rizvi, S.H.M.; Sushma; Mahdi, F.; Ahmad, I.; Singh, P.P. Intranasal exposure to silica nanoparticles induces alterations in pro-inflammatory environment of rat brain: Involvement of oxidative stress. Toxicol. Ind. Health 2017, 33, 119-132. [CrossRef]

11. Liu, X.; Sui, B.; Sun, J. Blood-brain barrier dysfunction induced by silica NPs in vitro and in vivo: Involvement of oxidative stress and Rho-kinase/JNK signaling pathways. Biomaterials 2017, 121, 64-82. [CrossRef] [PubMed] 
12. Mourdikoudis, S.; Pallares, R.M.; Thanh, N.T.K. Characterization techniques for nanoparticles: Comparison and complementarity upon studying nanoparticle properties. Nanoscale 2018, 10, 12871-12934. [CrossRef] [PubMed]

13. Yang, H.Y.; Yang, S.N.; Kong, J.L.; Dong, A.C.; Yu, S.N. Obtaining information about protein secondary structures in aqueous solution using Fourier transform IR spectroscopy. Nat. Protoc. 2015, 10, 382-396. [CrossRef] [PubMed]

14. Baker, M.J.; Trevisan, J.; Bassan, P.; Bhargava, R.; Butler, H.J.; Dorling, K.M. Using Fourier transform IR spectroscopy to analyze biological materials. Nat. Protoc. 2014, 9, 1771-1791. [CrossRef]

15. Escudero-Lourdes, C.; Uresti-Rivera, E.E.; Oliva-González, C.; Torres-Ramos, M.A.; Aguirre-Bañuelos, P.; Gandolfi, A.J. Cortical Astrocytes Acutely Exposed to the Monomethylarsonous Acid (MMAIII) Show Increased Pro-inflammatory Cytokines Gene Expression that is Consistent with APP and BACE-1: Over-expression. Neurochem. Res. 2016, 41, 2559-2572. [CrossRef]

16. Orozco-Ibarra, M.; Estrada-Sanchez, A.M.; Massieu, L.; Pedraza-Chaverri, J. Heme oxygenase-1 induction prevents neuronal damage triggered during mitochondrial inhibition: Role of $\mathrm{CO}$ and bilirubin. Int. J. Biochem. Cell Biol. 2009, 41, 1304-1314. [CrossRef]

17. Vazquez-Zapien, G.J.; Mata-Miranda, M.M.; Sanchez-Monroy, V.; Delgado-Macuil, R.J.; Perez-Ishiwara, D.G.; Rojas-Lopez, M. FTIR Spectroscopic and Molecular Analysis during Differentiation of Pluripotent Stem Cells to Pancreatic Cells. Stem Cells Int. 2016, 2016, 6709714. [CrossRef]

18. Mata-Miranda, M.M.; Guerrero-Ruiz, M.; Gonzalez-Fuentes, J.R.; Hernandez-Toscano, C.M.; Garcia-Andino, J.R.; Sanchez-Brito, M.; Vazquez-Zapien, G.J. Characterization of the Biological Fingerprint and Identification of Associated Parameters in Stress Fractures by FTIR Spectroscopy. Biomed. Res. Int. 2019, 2019, 1241452. [CrossRef]

19. Gonzalez-Reyes, S.; Orozco-Ibarra, M.; Guzman-Beltran, S.; Molina-Jijon, E.; Massieu, L.; Pedraza-Chaverri, J. Neuroprotective role of heme-oxygenase 1 against iodoacetate-induced toxicity in rat cerebellar granule neurons: Role of bilirubin. Free Radic. Res. 2009, 3, 214-223. [CrossRef]

20. Tejaswi, J.; Anirudh, K.V.S.; Majeti, L.R.; Kotagiri, D.; Shaik, K.B.; Chaitanya, K.V. Investigation of Biological Activity of Nanoparticles Using Cell Lines. In Model Organisms to Study Biological Activities and Toxicity of Nanoparticles; Siddhardha, B., Dyavaiah, M., Kasinathan, K., Eds.; Springer Nature: Berlin, Germany, 2020; pp. 117-138.

21. Rieppo, L.; Saarakkala, S.; Narhi, T.; Helminen, H.J.; Jurvelin, J.S.; Rieppo, J. Application of second derivative spectroscopy for increasing molecular specificity of fourier transform infrared spectroscopic imaging of articular cartilage. Osteoarthr. Cartil. 2012, 20, 451-459. [CrossRef]

22. Zelig, U.; Kapelushnik, J.; Moreh, R.; Mordechai, S.; Nathan, I. Diagnosis of Cell Death by Means of Infrared Spectroscopy. Biophys. J. 2009, 97, 2107-2114. [CrossRef]

23. Petibois, C.; Deleris, G. Chemical mapping of tumor progression by FT-IR imaging: Towards molecular histopathology. Trends Biotechnol. 2006, 24, 455-462. [CrossRef] [PubMed]

24. Kimber, J.A.; Kazarian, S.G. Spectroscopic imaging of biomaterials and biological systems with FTIR microscopy or with quantum cascade lasers. Anal. Bioanal. Chem. 2017, 409, 5813-5820. [CrossRef] [PubMed]

25. Petibois, C.; Wehbe, K.; Belbachir, K.; Noreen, R.; Deleris, G. Current Trends in the Development of FTIR Imaging for the Quantitative Analysis of Biological Samples. Acta Phys. Pol. A 2009, 115, 507-512. [CrossRef]

26. Fisichella, M.; Dabboue, H.; Bhattacharyya, S.; Saboungi, M.L.; Salvetat, J.P.; Hevor, T.; Guerin, M. Mesoporous silica nanoparticles enhance MTT formazan exocytosis in HeLa cells and astrocytes. Toxicol. In Vitro 2009, 23, 697-703. [CrossRef]

27. Marfin, Y.S.; Vashurin, A.S.; Rumyantsev, E.V.; Puhovskaya, S.G. Sol-gel synthesis of highly effective catalyst based on cobalt tetrasulfophthalocyanine complex and silicon oxide. J. Solgel. Sci. Technol. 2013, 66, 306-311. [CrossRef]

28. Mourant, J.R.; Yamada, Y.R.; Carpenter, S.; Dominique, L.R.; Freyer, J.P. FTIR spectroscopy demonstrates biochemical differences in mammalian cell cultures at different growth stages. Biophys. J. 2003, 85, 1938-1947. [CrossRef]

29. Kim, J.H.; Kim, C.S.; Ignacio, R.M.C.; Kim, D.H.; Sajo, M.E.J.; Maeng, E.H.; Qi, X.F.; Park, S.E.; Kim, Y.R.; Kim, M.K.; et al. Immunotoxicity of silicon dioxide nanoparticles with different sizes and electrostatic charge. Int. J. Nanomed. 2014, 9, 183-193. [CrossRef] 
30. Izak-Nau, E.; Kenesei, K.; Murali, K.; Voetz, M.; Eiden, S.; Puntes, V.F.; Duschl, A.; Madarász, E. Interaction of differently functionalized fluorescent silica nanoparticles with neural stem- and tissue-type cells. Nanotoxicology 2014, 8, 138-148. [CrossRef]

31. Sun, D.; Gong, L.; Xie, J.; He, X.; Chen, S.; Luodan, A.; Li, Q.; Gu, Z.; Xu, H. Evaluating the toxicity of silicon dioxide nanoparticles on neural stem cells using RNA-Seq. RSC Adv. 2017, 7, 47552-47564. [CrossRef]

32. Ye, Y.; Hui, L.; Lakpa, K.L.; Xing, Y.Q.; Wollenzien, H.; Chen, X.S. Effects of silica nanoparticles on endolysosome function in primary cultured neurons. Can. J. Physiol. Pharmacol. 2019, 97, 297-305. [CrossRef]

33. Hashimoto, M.; Imazato, S. Cytotoxic and genotoxic characterization of aluminum and silicon oxide nanoparticles in macrophages. Dent. Mater. 2015, 31, 556-564. [CrossRef] [PubMed]

34. McCracken, C.; Zane, A.; Knight, D.A.; Dutta, P.K.; Waldman, W.J. Minimal intestinal epithelial cell toxicity in response to short- and long-term food-relevant inorganic nanoparticle exposure. Chem. Res. Toxicol. 2013, 26, 1514-1525. [CrossRef] [PubMed]

35. Nabeshi, H.; Yoshikawa, T.; Matsuyama, K.; Nakazato, Y.; Tochigi, S.; Kondoh, S.; Hirai, T.; Akase, T.; Nagano, K.; Abe, Y.; et al. Amorphous nanosilica induce endocytosis-dependent ROS generation and DNA damage in human keratinocytes. Part. Fibre Toxicol. 2011, 8, 1. [CrossRef] [PubMed]

36. Nabeshi, H.; Yoshikawa, T.; Matsuyama, K.; Nakazato, Y.; Matsuo, K.; Arimori, A.; Isobe, M.; Tochigi, S.; Kondoh, S.; Hirai, T.; et al. Systemic distribution, nuclear entry and cytotoxicity of amorphous nanosilica following topical application. Biomaterials 2011, 32, 2713-2724. [CrossRef] [PubMed]

37. Reemst, K.; Noctor, S.C.; Lucassen, P.J.; Hol, E.M. The Indispensable Roles of Microglia and Astrocytes during Brain Development. Front. Hum. Neurosci. 2016, 10, 566. [CrossRef]

38. Schafer, D.P.; Stevens, B. Phagocytic glial cells: Sculpting synaptic circuits in the developing nervous system. Curr. Opin. Neurobiol. 2013, 23, 1034-1040. [CrossRef]

39. Wakida, N.M.; Cruz, G.M.S.; Ro, C.C.; Moncada, E.G.; Khatibzadeh, N.; Flanagan, L.A. Phagocytic response of astrocytes to damaged neighboring cells. PLoS ONE 2018, 13, e0196153. [CrossRef]

40. Fernández-Bertólez, N.; Costa, C.; Brandão, F.; Kiliç, G.; Duarte, J.A.; Teixeira, J.P. Toxicological assessment of silica-coated iron oxide nanoparticles in human astrocytes. Food Chem. Toxicol. 2018, 118, 13-23. [CrossRef]

41. Choi, J.; Zheng, Q.; Katz, H.E.; Guilarte, T.R. Silica-based nanoparticle uptake and cellular response by primary microglia. Environ. Health Perspect. 2010, 118, 589-595. [CrossRef]

42. Megias, L.; Guerri, C.; Fornas, E.; Azorin, I.; Bendala, E.; Sancho-Tello, M. Endocytosis and transcytosis in growing astrocytes in primary culture. Possible implications in neural development. Int. J. Dev. Biol. 2000, 44, 209-221. [PubMed]

43. Wilson, C.L.; Natarajan, V.; Hayward, S.L.; Khalimonchuk, O.; Kidambi, S. Mitochondrial dysfunction and loss of glutamate uptake in primary astrocytes exposed to titanium dioxide nanoparticles. Nanoscale 2015, 7, 18477-18488. [CrossRef] [PubMed]

44. Xu, L.; Dan, M.; Shao, A.; Cheng, X.; Zhang, C.; Yokel, R.A.; Takemura, T.; Hanagata, N.; Niwa, M.; Watanabe, D. Silver nanoparticles induce tight junction disruption and astrocyte neurotoxicity in a rat blood-brain barrier primary triple coculture model. Int. J. Nanomed. 2015, 10, 105-118. [CrossRef]

45. Yang, Y.; Du, X.J.; Wang, Q.; Liu, J.W.; Zhang, E.G.; Sai, L.L. Mechanism of cell death induced by silica nanoparticles in hepatocyte cells is by apoptosis. Int. J. Mol. Med. 2019, 44, 903-912. [CrossRef]

46. Iavicoli, I.; Leso, V.; Fontana, L.; Calabrese, E.J. Nanoparticle Exposure and Hormetic Dose-Responses: An Update. Int. J. Mol. Sci. 2018, 19, 805. [CrossRef]

47. Mytych, J.; Wnuk, M.; Rattan, S.I.S. Low doses of nanodiamonds and silica nanoparticles have beneficial hormetic effects in normal human skin fibroblasts in culture. Chemosphere 2016, 148, 307-315. [CrossRef] [PubMed]

48. Krętowski, R.; Kusaczuk, M.; Naumowicz, M.; Kotyńska, J.; Szynaka, B.; Cechowska-Pasko, M. The Effects of Silica Nanoparticles on Apoptosis and Autophagy of Glioblastoma Cell Lines. Nanomaterials (Basel) 2017, 7, 230. [CrossRef]

49. Arnoldussen, Y.J.; Kringlen Ervik, T.; Baarnes Eriksen, M.; Kero, I.; Skaug, V.; Zienolddiny, S. Cellular Responses of Industrially Relevant Silica Dust on Human Glial Cells in Vitro. Int. J. Mol. Sci. 2019, 20, 358. [CrossRef] [PubMed]

50. Zhou, M.; Xie, L.L.; Fang, C.J.; Yang, H.; Wang, Y.J.; Zhen, X.Y. Implications for blood-brain-barrier permeability, in vitro oxidative stress and neurotoxicity potential induced by mesoporous silica nanoparticles: Effects of surface modification. RSC Adv. 2016, 6, 2800-2809. [CrossRef] 
51. Yang, X.F.; Liu, J.J.; He, H.W.; Zhou, L.; Gong, C.M.; Wang, X.M. SiO2 nanoparticles induce cytotoxicity and protein expression alteration in HaCaT cells. Part. Fibre Toxicol. 2010, 7, 1. [CrossRef]

52. Lopez-Fabuel, I.; Le Douce, J.; Logan, A.; James, A.M.; Bonvento, G.; Murphy, M.P. Complex I assembly into supercomplexes determines differential mitochondrial ROS production in neurons and astrocytes. Proc. Natl. Acad. Sci. USA 2016, 113, 13063-13068. [CrossRef] [PubMed]

53. Yang, X.F.; He, C.E.; Li, J.; Chen, H.B.; Ma, Q.; Sui, X.J. Uptake of silica nanoparticles: Neurotoxicity and Alzheimer-like pathology in human SK-N-SH and mouse neuro2a neuroblastoma cells. Toxicol. Lett. 2014, 229, 240-249. [CrossRef] [PubMed]

54. Gélinas, S.; Chapados, C.; Beauregard, M.; Gosselin, I.; Martinoli, M.G. Effect of oxidative stress on stability and structure of neurofilament proteins. Biochem. Cell Biol. 2000, 78, 667-674. [CrossRef] [PubMed]

55. Xie, H.J.; Wu, J. Silica nanoparticles induce alpha-synuclein induction and aggregation in PC12-cells. Chem. Biol. Interact. 2016, 258, 197-204. [CrossRef]

(C) 2020 by the authors. Licensee MDPI, Basel, Switzerland. This article is an open access article distributed under the terms and conditions of the Creative Commons Attribution (CC BY) license (http://creativecommons.org/licenses/by/4.0/). 